\title{
A “User-Knowledge-Product” Co-Creation Cyberspace Model for Product Innovation
}

\author{
Yu Wang $\mathbb{D},{ }^{1}$ Jiacong Wu $\mathbb{D},{ }^{2}$ Ru Zhang $\mathbb{D}^{1},{ }^{1}$ Sara Shafiee, ${ }^{3}$ and Cheng $\mathrm{Li}^{1}$ \\ ${ }^{1}$ School of International Business, Jinan University (Zhuhai Campus), Zhuhai 519070, China \\ ${ }^{2}$ School of Management, Jinan University, Guangzhou 510632, China \\ ${ }^{3}$ Department of Mechanical Engineering, Technical University of Denmark, Kgs. Lyngby 2800, Denmark \\ Correspondence should be addressed to Jiacong Wu; skywu@stu2017.jnu.edu.cn and Ru Zhang; zhangru@stu2016.jnu.edu.cn
}

Received 9 April 2019; Accepted 8 October 2019; Published 10 January 2020

Guest Editor: Murari Andrea

Copyright (C) $2020 \mathrm{Yu}$ Wang et al. This is an open access article distributed under the Creative Commons Attribution License, which permits unrestricted use, distribution, and reproduction in any medium, provided the original work is properly cited.

To benefit from users' co-creation knowledge in online communities, enterprises need effective methods to discover and manage co-creation users and knowledge as suggested in existing research. However, the existing methods still have their own limitations when analysing different relationships and networks. Therefore, first, this paper proposes a co-creation cyberspace super-network model for product innovation from a "user-knowledge-product" perspective to integrate the co-creation information of users, knowledge, and products. Second, to increase the accuracy of discovering, managing, and using the co-creation knowledge, three subnetworks including co-creation user network, co-creation knowledge network, and co-creation product network as well as the relationships among them are constructed and improved. Third, a well-known co-creation community in China is selected as a case to verify the feasibility and validity of the proposed model for enterprise's product innovation. Three subnetworks and the mapping relationships among them are constructed and visualized based on the introduced User-Knowledge-Product Cyberspace model. The results from the case study validate the co-creation cyberspace constructed in this paper and provide enterprises with a comprehensive and detailed integration framework analysis model. Hence, the enterprises can use this model for user discovery, product innovation knowledge mining, and dynamic innovation knowledge basement and forecast hotspot trend in cocreation communities.

\section{Introduction}

As product innovation has become more complex and its costs have increased in recent years, enterprises can no longer realize continuous innovation through their internal innovation capabilities; rather they increasingly co-create with external stakeholders [1]. With the advances in information technology, online co-creation communities with a large volume of user-generated content provide enterprises a new way to communicate with customers $[2,3]$. In online co-creation communities, customers can interact actively with each other and are absorbed in product development process. They provide inputs in the form of ideas, suggestions, and solutions, serving as product conceptualizers, product designers, product testers, product observers, and product marketers [4]. Therefore, enterprises can select the pertinent ideas for their innovation development to improve their products and service, expand markets, and even accelerate innovation processes $[3,5]$. Furthermore, enterprises can also improve customer relationship management, such as brand loyalty, brand trust, and brand commitment in online co-creation communities [6-8].

As argued by Irani et al. [9], users' co-creation knowledge is a unique and nonduplicated resource and serves as a driven force in promoting product innovation. In a complex social network system, the co-creation knowledge generated between enterprises and users is critical for enterprises' product innovation and their continued competitiveness in markets [10]. However, enterprises can hardly utilize cocreation knowledge in online communities for efficient product innovation [11] and the probable reasons are as follows. (1) There is overload of information and overflow of 
spam messages that present significant challenges in cocreation knowledge discovery, management, and application [11]. (2) It is difficult to manage online co-creation communities as they are easy to access with no time and geographical constraint [12]. (3) The knowledge from cocreation communities is unstructured, diverse, and heterogeneous [13], which is one of the reasons in hindering knowledge discovery and classification, and product innovation [14].

The issue of constructing a co-creation knowledge network to discover, manage, and apply co-creation knowledge for product innovation has been recognized by a few research [14-17]. However, most of the existing research has its own limitations when analysing different relationships of users and knowledge and constructing different subnetworks. First, most of the existing research ignored the collaborative relationship between co-creation users when constructing co-creation user network [14], which influences the accuracy of identifying leading users. Second, when constructing co-creation knowledge network, the cooccurrence relationship of knowledge points was considered, but the similarity relationship among knowledge points was not taken into account, resulting in information overload. In addition, lack of comprehensive consideration of knowledge point weights lead to inaccurate identification of hot knowledge points. Third, most of the existing research only considered two-tier networks, the co-creation users and knowledge network [14], which influences the accuracy and efficiency when mapping co-creation knowledge with product innovation. Therefore, to address these limitations, this paper aims to answer the following research questions: (1) How to fully consider the relationships between cocreation users to better manage users and identify leading users? (2) How to integrate highly similar co-creation knowledge points to avoid information overload and comprehensively consider knowledge point weights to better identify hot co-creation knowledge points? (3) How to construct a product network (includes the nodes of product names and product feature network) to map with co-creation knowledge points for more accurate product innovation?

To address those research questions and considering the limitations of the existing research, we develop a co-creation cyberspace super-network model for product innovation to help enterprises to discover, manage and apply co-creation knowledge in an effective way. This paper contributes from three different perspectives. The first is to understand the relationships among co-creation users more comprehensively and discover the leading co-creation users more accurately. So, both the interaction and collaboration relationships among co-creation users are considered when constructing co-creation user network. Second, to avoid information overload, this paper uses the words similarity algorithm to avoid the repeated calculation of co-creation knowledge when constructing co-creation knowledge network. In addition, knowledge frequency, attention, and character are considered adequately when constructing knowledge weight set. Third, a co-creation product network is further constructed to map with co-creation user network and co-creation knowledge network for better product innovation.

This paper is organized as follows: The next section reviews relevant studies already conducted in this research area. Section 3 describes the construction of the "userknowledge-product" co-creation cyberspace model. Three subnetworks are constructed and the mapping relationships among them are analysed in details. Section 4 uses a case study of a well-known co-creation community in China to visualise and validate the proposed co-creation cyberspace model. Finally, contribution to theory and industry and limitations and future directions of this paper are discussed.

\section{Literature Review}

In recent years, in order to mine the value of co-creation knowledge and take advantage of the useful co-creation knowledge for business purpose, various research areas have been explored. However, there are three streams of literature relevant to this paper. First, several studies researched in online community knowledge creation process and mechanism to understand how users participate in online communities and generate co-creation knowledge. Second, some studies further researched in online community knowledge discovery and management and proposed multiple methods and tools for it. Third, few studies further investigated in knowledge application to explore how the discovered and managed co-creation knowledge can be used for business purpose. The three streams of relevant literature are reviewed in subsections below in details.

\subsection{Studies on Online Community Knowledge Creation Pro-} cesses and Mechanisms. Knowledge is created through two generic processes: combination and exchange [18], and thus online community knowledge creation processes and mechanisms should be studied from not only an individual perspective but also a community perspective [19]. Two streams of studies have examined knowledge creation. First, from an individual perspective, leading users are often important initiators and contributors of innovative knowledge such as product concepts. For example, Von Hippel [20] proposed that leading users can present the main requirements which will become general in a marketplace in few months or years, and they can provide new product concept and design data as well. In addition, as a strong cornerstone for product innovation, leading users often maintain more frequent interactions with other members in the community and inspire other users to participate in co-creation process [21]. Second, from a community perspective, interactions in one community are the key driver in knowledge creation [1]. For example, Hau and Kim [22] proposed that social capital is the major concern that prompts users to share their innovative knowledge voluntarily. The greater social capital and relationship facilitate the access of individuals to other sources of knowledge within and outside the organisation and increase their willingness and efficiency of knowledge cocreation [18]. Hafkesbrink and Schroll [23] found that, 
basically, co-creation community is a learning community involving users and managers and they collaboratively conduct a learning and innovation process.

However, such studies can only keep practitioners informed of the gained benefits from co-creation knowledge for enterprises' product innovation. There is limited practicability to provide guidance on how to better coordinate online users" innovative knowledge creation and the internal new product development in an enterprise. Therefore, there is a great practical significance and theoretical value in analysing their connection.

\subsection{Studies on Online Community Knowledge Discovery and} Management. As for online knowledge discovery and management, existing research has explored multiple methods and tools for analysing the co-creation knowledge network structures and knowledge development process such as concept map, domain knowledge map, and knowledge super-network. Divakaran [24] proposed a "communityaided brand concept map" to collect user-generated data and analyse the evolution and the dynamic pattern of brand associations. According to the domain feature set defined by domain experts, Hao et al. [25] proposed a domain knowledge map construction method using latent semantic analysis, so that various types of knowledge can be classified into different domains based on their semantics for better knowledge management. Due to the lack of research in the construction of semantic knowledge base and the semantic expression model in the context of big data, Liu et al. [26] proposed a model and construction method on dynamic knowledge network. Liao et al. [27] proposed modelling and analysing methods of user-innovation knowledge in enterprise communities based on a weighted knowledge network, so that the importance of each knowledge and the closeness among each knowledge can be clearly indicated in the network. Furthermore, based on a super-network model for public innovation, Tang et al. [14] proposed an analytical framework for enterprises to manage all elements of knowledge in online communities conveniently. Comprehensively considering the users, attention, and frequency of knowledge, the authors constructed user network, text network, and semantics network of knowledge and the relationship among them.

Such research provided great methods and technical support for the discovery and management of co-creation knowledge and they could be the base of this study. However, these knowledge network construction methods also have their own limitations which need to be improved in this study. For example, when analysing the relationships among cocreation users, only the collaboration relationship was considered and the interaction relationship was ignored [14], which create biases for the accurate discovery and management of co-creation users. The concern, reply, forwarding, and comment among co-creation users are more and more frequent, and this interaction information among users is valuable and necessary to be taken into account for accurate co-creation user identification. Furthermore, when analysing the relationships between knowledge points, only the cooccurrence of knowledge points was considered, but the similarity relationship among knowledge points was not taken into account $[14,26,27]$, resulting in information overload and inaccurate hot co-creation knowledge discovery. As different users may use similar but different words to express same meaning, Wang and Shao [28] have indicated the importance of considering the similarity among words and merging similar words for more accurate word frequency statistics. It is obvious that the management and discovery of co-creation knowledge will be disturbed without considering the similarity among knowledge. Moreover, the factors considered when setting the knowledge point weights were not comprehensive enough [14, 25-27], interfering the discovery of hot knowledge. Based on a Co-word model [28], keywords with different position, part-of-speech, or span have different importance significantly. Therefore, these characters of knowledge points are necessary to be considered for more comprehensive cocreation knowledge management and discovery.

2.3. Studies on Knowledge Application. Chen et al. [15] proposed a knowledge super-network model to provide support for knowledge acquisition and integration in the process of innovation, and the exploration and evaluation of innovation issues. Yang et al. [16] proposed a knowledgedriven product innovation design model based on complex networks according to the application characteristics of design knowledge in innovation and many-to-many relationship of functions, behaviours, and structures. Yassine and Bradley [17] built a knowledge network model based on data acquisition, transformation, and utilization to support product development and design.

Such research sheds light on co-creation knowledge application and gives support to enterprises during their product innovation process. However, most of the existing research only considered two-tier networks, the co-creation user network, and the co-creation knowledge network, which influence the accuracy and efficiency when mapping co-creation knowledge with product innovation.

2.4. Literature Summary. This section presented and overview on different research available on online community knowledge co-creation, online community knowledge discovery and management (e.g. concept map, various knowledge network, etc.), and also business cases and applications for the industries. Table 1 summarizes few discussed research in the previous subsections and categorizes them based the area of application and lists the positive contribution and remaining gaps in the field "Detailed contribution $(+) / G a p$ in the research (-)." The table has been divided into four columns to determine the research contribution in three cocreation network construction. As it is illustrated, most of the previous research focused on co-creation knowledge network construction, and we rarely found studies on co-creation user network and product network construction, which are also valuable and important for product innovation. Therefore, it is the motivation and contribution of this paper to extend the previous co-creation network to a more comprehensive and systematic "user-knowledge-product" co-creation cyberspace model for better product innovation. 
TABle 1: Previous research summary.

\begin{tabular}{|c|c|c|c|c|}
\hline $\begin{array}{l}\text { Related } \\
\text { research }\end{array}$ & $\begin{array}{l}\text { Co-creation } \\
\text { user network }\end{array}$ & $\begin{array}{c}\text { Co-creation } \\
\text { knowledge } \\
\text { network }\end{array}$ & $\begin{array}{l}\text { Co-creation } \\
\text { product network }\end{array}$ & Detailed contribution $(+)$ /gap in the research $(-)$ \\
\hline $\begin{array}{l}\text { Divakaran } \\
{[24]}\end{array}$ & & $\checkmark$ & & $\begin{array}{l}\text { + Analysed the evolution and the dynamic pattern of brand } \\
\text { associations. } \\
\text { - The considered weights and relationship of knowledge are } \\
\text { simple. }\end{array}$ \\
\hline Hao et al. [25] & & $\checkmark$ & & $\begin{array}{l}\text { + Various types of knowledge can be classified into different } \\
\text { domains based on their semantics for better knowledge } \\
\text { management. } \\
\text { - Only the co-occurrence relationship among knowledge was } \\
\text { considered. The weights of knowledge were neglected. }\end{array}$ \\
\hline Liu et al. [26] & & $\checkmark$ & & $\begin{array}{l}\text { + Constructed a semantic expression model of dynamic } \\
\text { knowledge network in the context of big data. } \\
\text { - Only considered the semantic relationship among knowledge. } \\
\text { No attention to the relation between user and knowledge and } \\
\text { product for product innovation. }\end{array}$ \\
\hline Liao et al. [27] & & $\checkmark$ & & $\begin{array}{l}\text { + The importance of each knowledge and the closeness among } \\
\text { each knowledge can be clearly indicated in the network. } \\
\text { - Some character weights of knowledge and the similarity } \\
\text { relationship among knowledge were neglected. }\end{array}$ \\
\hline Tang et al. [14] & $\checkmark$ & $\checkmark$ & & $\begin{array}{l}\text { + Comprehensively considering the users, attention, and } \\
\text { frequency of knowledge, the authors constructed user network, } \\
\text { text network, and semantics network of knowledge and the } \\
\text { relationship among them. } \\
\text { - Some character weights of knowledge and the similarity } \\
\text { relationship among knowledge were neglected. }\end{array}$ \\
\hline $\begin{array}{l}\text { Chen et al. } \\
\text { [15] }\end{array}$ & & $\checkmark$ & & $\begin{array}{l}\text { + Support for knowledge acquisition and integration in the } \\
\text { process of innovation and the exploration and evaluation of } \\
\text { innovation issues. } \\
\text { - No attention to the relation between user and knowledge. }\end{array}$ \\
\hline $\begin{array}{l}\text { Yang et al. } \\
{[16]}\end{array}$ & & $\checkmark$ & & $\begin{array}{l}\text { + Proposed a knowledge-driven product innovation design model. } \\
\text { - No attention to the relation between user and knowledge. }\end{array}$ \\
\hline $\begin{array}{l}\text { Yassine and } \\
\text { Bradley [17] }\end{array}$ & & $\checkmark$ & & $\begin{array}{l}\text { + Constructed a knowledge network model based on data } \\
\text { acquisition, transformation, and utilization to support product } \\
\text { development and design. } \\
\text { - No attention to the relation between user and knowledge. }\end{array}$ \\
\hline This paper & $\checkmark$ & $\checkmark$ & $\checkmark$ & $\begin{array}{l}\text { + (1) Combined some of the advantages of the construction of co- } \\
\text { creation user and knowledge network in the related literature. } \\
\text { (2) Further considered some important but neglected weights and } \\
\text { relationships of users and knowledge to make the network more } \\
\text { comprehensive. } \\
\text { (3) Extend the previous network to a more systematic "user- } \\
\text { knowledge-product" co-creation cyberspace model for better } \\
\text { product innovation. } \\
\text { - The comparative analysis with the related research is required in } \\
\text { the future to prove the priority of the model. }\end{array}$ \\
\hline
\end{tabular}

\section{Construction of the "User-Knowledge- Product" Co-Creation Cyberspace Model}

To address the limitations ascertained from the literature, as summarized in Section 2, we propose a "user-knowledgeproduct" co-creation cyberspace super-network model to provide a more comprehensive, detailed, and integrated analysis model for user discovery and management and product innovative knowledge mining and management, which is shown in Figure 1.
This model is novel due to the following design considerations:

(1) When constructing the co-creation user network, not only collaboration relationship but also interaction relationship among co-creation users are considered for better user management and leading user identification. Based on the attention relationship, reply relationship, forwarding relationship, and review relationship among co-creation users, the direct interaction relationship among co-creation users is built. 


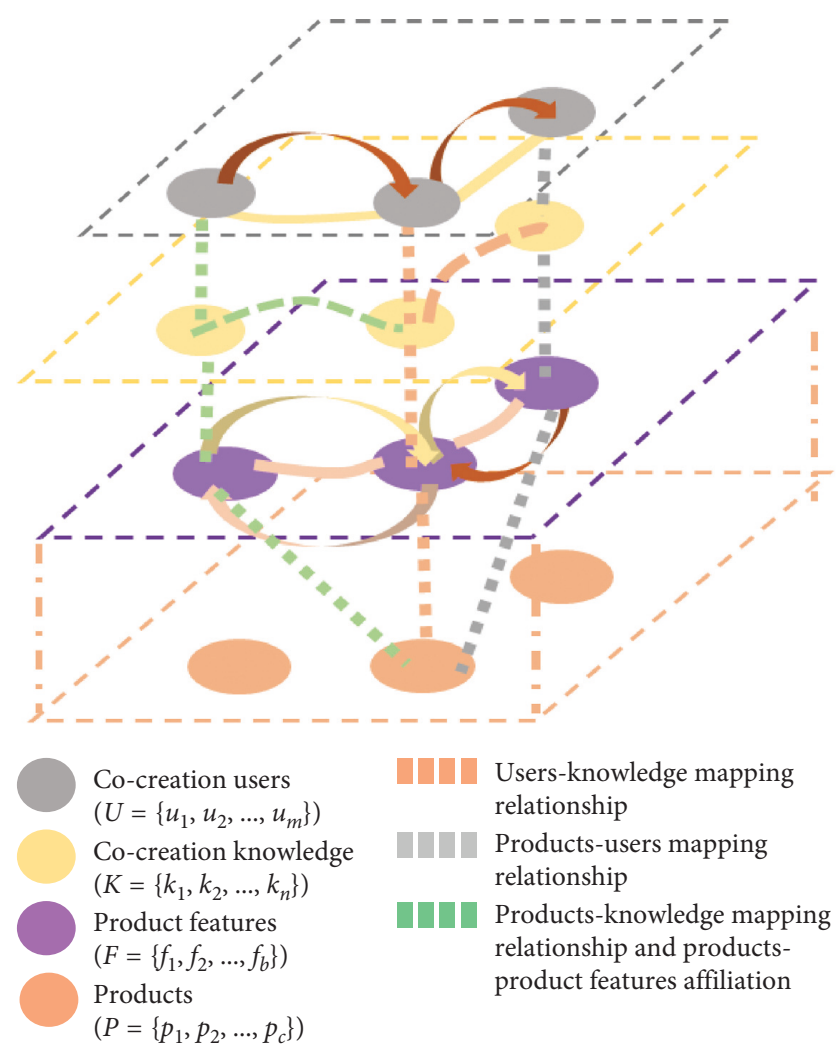

FIGURE 1: Co-creation knowledge network cyberspace for product innovation.

(2) When constructing the co-creation knowledge network, repetitiveness and similarities among knowledge points are further considered by calculating the semantic similarities among them to avoid information overload. Besides, in addition to the frequency and attention weights of knowledge points, character weights including the position, part-ofspeech, and span of the knowledge points are considered for more accurate hot knowledge point identification.

(3) A co-creation product network is constructed to map with the previous two-tier co-creation network for applying co-creation knowledge into product innovation. Thus, a comprehensive co-creation cyberspace for product innovation is integrated for enterprises to better manage the co-creation users and knowledge systematically and identify the useful information for product innovation.

Based on the earlier version of this paper presented in 11th CIRP Conference on Industrial Product-Service Systems [29], three subnetworks are constructed and the mapping relationships among them are analysed in detail in the following subsections.

3.1. Co-Creation User Network Construction. With regard to co-creation users, an online social network model [30] reveals two major factors of social network formation: social choice and social influence [31]. Hence, a multidimensional online interest network model [32] classifies co-creation user relationship into interaction relationship caused by social influence and collaboration relationship caused by social choice, which are shown in Table 2.

Most of the existing research only considered the collaboration relationship and neglected the interaction relationship among co-creation users when constructing the cocreation user network [14], which resulted in inaccurate discovery of co-creation users and poor management in online co-creation communities. To address this limitation, this paper uses co-creation users as nodes and uses their interaction and collaboration relationships as two-dimensional edges to construct co-creation user network, shown in Figure 2.

The co-creation user network " $G_{U}$ " is expressed as

$$
G_{U}=\left\{U, E_{U D}, E_{U A}, W\left(E_{U D}\right), W\left(E_{U A}\right)\right\},
$$

where " $U$ " is the set of co-creation users with amount " $m$ " as follows:

$$
U=\left\{u_{1}, u_{2}, \ldots, u_{m}\right\} .
$$

The co-creation user relationship set " $E_{U}$ " includes interaction relationship set " $E_{U D}$ " with weight set " $W\left(E_{U D}\right)$ " and collaboration relationship set " $E_{U A}$ " with weight set " $W\left(E_{U A}\right)$." As mentioned in Table 2, the co-creation user network includes two parts:

(1) The interaction relationship set of co-creation users " $E_{U D}$ " is established based on attention relationship, reply relationship, forwarding relationship, and review relationship. If user " $u_{j}$ " pays attention, responds, forwards, or comments on user " $u_{i}$ " for more than " $w_{u d}$ " times, an interaction relationship " $e_{u d}\left(u_{i}, u_{j}\right)$ " is constructed from user " $u_{j}$ " to user " $u_{i}$," as shown in Figure 3.

The interaction relationship set of co-creation users and its weight set are expressed as follows:

$$
\begin{aligned}
E_{U D} & =\left\{\left(e_{u d}\left(u_{i}, u_{j}\right)\right) \mid w\left(u_{i}, u_{j}\right), \geq w_{u d}\right\}, \\
W\left(E_{U D}\right) & =\left\{\left(w\left(u_{i}, u_{j}\right)\right) \mid w\left(u_{i}, u_{j}\right) \geq w_{u d}\right\} .
\end{aligned}
$$

(2) The collaboration relationship set of co-creation users " $E_{U A}$ " is established based on common friends and common topic participation. If the amount of collaboration activities " $w\left(u_{i}, u_{j}\right)$ " between user " $u_{i}$ " and user " $u_{j}$ " is not less than " $w_{u a}$ " times, a collaboration relationship " $e_{u a}\left(u_{i}, u_{j}\right)$ " is constructed between them. The conceptual diagram is shown in Figure 4.

The collaboration relationship set of co-creation users and its weight set are expressed as follows:

$$
\begin{aligned}
E_{U A} & =\left\{\left(e_{\text {ua }}\left(u_{i}, u_{j}\right)\right) \mid w\left(u_{i}, u_{j}\right) \geq w_{\text {ua }}\right\}, \\
W\left(E_{U A}\right) & =\left\{\left(w\left(u_{i}, u_{j}\right)\right) \mid w\left(u_{i}, u_{j}\right) \geq w_{\text {ua }}\right\} .
\end{aligned}
$$


TABLE 2: Types of co-creation user relationships.

\begin{tabular}{lccc}
\hline User relationship & $\begin{array}{c}\text { Formation } \\
\text { mechanism }\end{array}$ & User behaviour & Network type \\
\hline Interaction & Social influence & $\begin{array}{c}\text { Concern, reply, forwarding, comment } \\
\text { Common friend's attention, common topic } \\
\text { participation and common post comments }\end{array}$ & $\begin{array}{c}\text { Direct weighted interaction network } \\
\text { Indirect weighted collaboration network }\end{array}$ \\
\hline
\end{tabular}

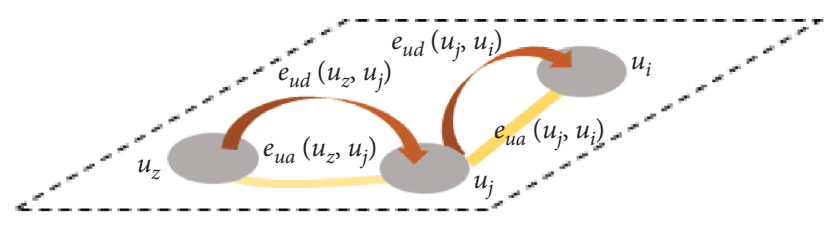

Co-creation users

Direct relationship

Indirect relationship

Figure 2: Co-creation user network.
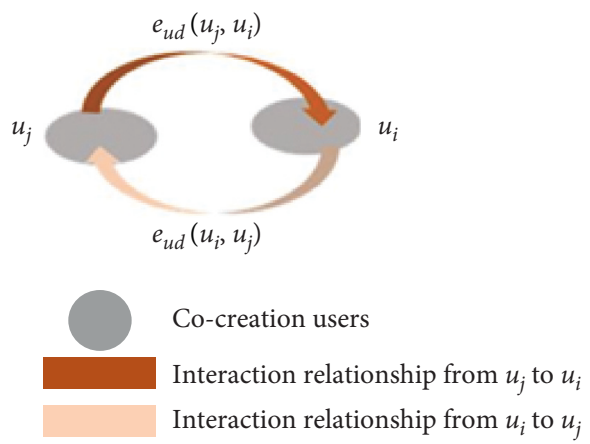

Figure 3: Co-creation user interaction network.

3.2. Co-Creation Knowledge Network Construction. Most of the existing research only considered the co-occurrence relationship and neglected the similarity relationship among co-creation knowledge points when constructing the cocreation knowledge network [14], which resulted in information overload, repeated calculation of co-creation knowledge points, and interference of hot knowledge discovery. In addition, there is still enough room for further improvements regarding the construction of knowledge point weight sets, which will interfere with the accuracy of hot knowledge point discovery. To address these limitations, this paper uses knowledge point keywords as nodes; uses attention, frequency, and character of them as their weights; and uses co-occurrence and similarity relationships as twodimensional edges to construct co-creation user network, as shown in Figure 5.

The co-creation knowledge network " $G_{K}$ " is expressed as $G_{K}=\left\{K, Q(K), H(K), O(K), E_{K C}, E_{K S}, W\left(E_{K C}\right), W\left(E_{K S}\right)\right\}$,

where " $K$ " is knowledge point set with frequency weight set " $Q(K)$," attention weight set " $H(K)$," and character weight set “ $O(K)$. "“ $E_{K}$ ” is knowledge relationship set including

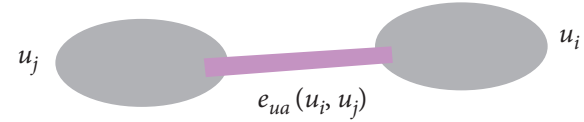

Co-creation users

Collaboration relationship

FIgURE 4: Co-creation user collaboration network.

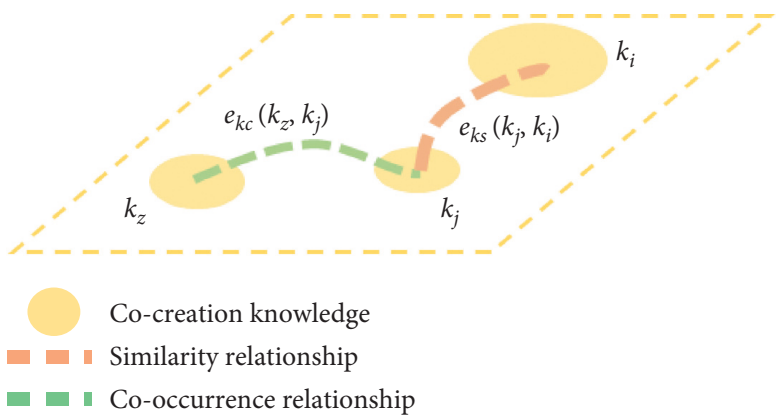

FIgURE 5: Co-creation knowledge network.

co-occurrence relationship set " $E_{K C}$ " with weight set " $W\left(E_{K C}\right)$ " and similarity relationship " $E_{K S}$ " with weight set "W $\left(E_{K S}\right)$." The knowledge point set with various weight sets and the knowledge relationship sets are constructed, respectively, in details as follows.

3.2.1. The Weight Sets of Knowledge Points. This paper comprehensively considers the frequency, attention, and characters of co-creation knowledge points to establish knowledge point weight sets, as described below:

(1) The frequency weight set of knowledge points " $Q(K)$ " is established based on their mentioned frequency, which is calculated as follows:

$$
q\left(k_{i}\right)=\sum_{j=1}^{a} \eta\left(k_{i}, b_{j}\right),
$$

where " $\eta\left(k_{i}, b_{j}\right)=1$ " indicates that the knowledge point " $k_{i}$ " is the keyword of the post " $b_{j}$ "; otherwise, “ $\eta\left(k_{i}, b_{j}\right)=0$." Hence, the knowledge point frequency weight set is expressed as

$$
Q(K)=\left\{q\left(k_{i}\right) \mid k_{i} \in\left\{k_{1}, k_{2}, \ldots, k_{n}\right\}\right\}
$$


(2) The attention weight set of knowledge points " $H(K)$ " is established based on the browsing popularity and response heat of their carrier post, which is calculated as follows:

$$
h\left(k_{i}\right)=\sum_{j=1}^{a}\left[h\left(b_{j}\right) * \eta\left(k_{i}, b_{j}\right)\right],
$$

where " $h\left(b_{j}\right)$ " is the attention of the knowledge point, " $k_{i}$ " 's carrier post " $b_{j}$ " including browse popularity " $\mathrm{HB}\left(b_{j}\right)$ " and response heat " $\mathrm{HR}\left(b_{j}\right)$," which is calculated as follows [27]:

$$
\begin{aligned}
h\left(b_{j}\right)= & \alpha * \operatorname{HB}\left(b_{j}\right)+\beta * \operatorname{HR}\left(b_{j}\right) \\
= & \alpha * \frac{v\left(b_{j}\right)}{\sqrt{\sum_{j=1}^{a} v^{2}\left(b_{j}\right)}} * e^{v\left(b_{j}\right) / \sqrt{\sum_{j=1}^{a} v\left(b_{j}\right)}} \\
& +\beta * \frac{r\left(b_{j}\right)}{\sqrt{\sum_{j=1}^{a} r^{2}\left(b_{j}\right)}} * e^{r\left(b_{j}\right) / \sqrt{\sum_{j=1}^{a} r\left(b_{j}\right)}},
\end{aligned}
$$

where " $\alpha$ " and " $\beta$ " represent the importance of the reply and browsing behaviour, respectively, " $v\left(b_{j}\right)$ " is the browse amount of the post " $b_{j}$ " and " $r\left(b_{j}\right)$ " is the reply amount of the post " $b_{j}$."

(3) The character weight set of knowledge points " $O(K)$ " is established based on their position, partof-speech, and span [28] including position weight set " $O_{L}(K)$," part-of-speech weight set " $O_{R}(K)$," and span weight set " $O_{T}(K)$."

For the position weight set of knowledge points " $O_{L}(K)$," the importance of knowledge points in different position of a post varies significantly. For example, knowledge points in the title of a post can summarize the main idea of the post, which should be paid more attention to. Thus, knowledge points in different position should be weighted differently, which is expressed as

$$
\begin{aligned}
O_{L}(K) & =\left\{\left(o_{l}\left(k_{i}\right)\right) \mid i=1,2, \ldots, n\right\} \\
\text { s.t. } o_{l}\left(k_{i}\right) & =\left\{\begin{array}{l}
o_{l_{1}} \text { (title) } \\
o_{l_{2}} \text { (text) } \\
o_{l_{3}} \text { (comment) }
\end{array} 1 \geq o_{l_{1}} \geq o_{l_{2}} \geq o_{l_{3}}>0 .\right.
\end{aligned}
$$

For the part-of-speech weight set of knowledge points " $O_{R}(K)$," similarly, the importance of knowledge points with different part-of-speech varies significantly. A noun knowledge points can better represent innovative topics and their connotations [28]. Therefore, knowledge points of different part-of-speech should be weighted differently, which is expressed as

$$
\begin{aligned}
O_{R}(K) & =\left\{\left(o_{r}\left(k_{i}\right)\right) \mid i=1,2, \ldots, n\right\} \\
\text { s.t. } o_{r}\left(k_{i}\right) & =\left\{\left\{\begin{array}{l}
o_{r_{1}} \text { (nouns) } \\
o_{r_{2}} \text { (other) }
\end{array} 1 \geq o_{r_{1}}>o_{r_{2}}>0 .\right.\right.
\end{aligned}
$$

For the span weight set of knowledge points " $\mathrm{O}_{T}(K)$," a knowledge point with larger span indicates that it can represent the main idea of a post more, so that it should be weighed greater. Therefore, the span weight of knowledge points is calculated as

$$
o_{t}\left(k_{i}\right)=\frac{p n}{3},
$$

where "pn" indicates how many parts of a post the knowledge points are mentioned in, including title, text, and comments part.

3.2.2. The Co-Creation Knowledge Relationship Set. The cocreation user relationship set " $E_{K}$ " includes co-occurrence relationship set " $E_{K C}$ " with weight set " $W\left(E_{K C}\right)$ " and similarity relationship set " $E_{K S}$ " with weight set " $W\left(E_{K S}\right)$ " and is described in details as follows:

(1) The co-occurrence relationship set of knowledge points " $E_{K C}$ " is established based on the co-occurrence of knowledge points. If the co-occurrence frequency " $w\left(k_{i}, k_{j}\right)$ " between two knowledge points is not less than " $w_{k c}$ " a co-occurrence relationship is constructed between them. And the co-occurrence relationship set of knowledge points " $E_{K C}$ " and its weight set are expressed as

$$
\begin{array}{r}
E_{K C}=\left\{e_{k c}\left(k_{i}, k_{j}\right) \mid w\left(k_{i}, k_{j}\right) \geq w_{k c}\right\}, \\
W\left(E_{K C}\right)=\left\{w\left(k_{i}, k_{j}\right) \mid w\left(k_{i}, k_{j}\right) \geq w_{k c}\right\} .
\end{array}
$$

(2) The similarity relationship set of knowledge points " $E_{K S}$ " is established based on the similarity " $s\left(k_{i}, k_{j}\right)$ " between knowledge points calculated by the words similarity algorithm based on Tongyici Cilin [28]. According to Tongyici Cilin, similarity " $s\left(k_{i}, k_{j}\right)$ " between knowledge points " $k_{i}$ " and " $k_{j}$ " is calculated by using the amount of knowledge points in the word forest to get semantic distance and similarity. The specific calculation method is shown in Table 3 .

In Table 3, " $n$ " is the amount of nodes in one branch layer where the knowledge point word is located and " $m$ " is the distance between two branches and the coefficients are generally customized and optimized according to experimental conditions. If the similarity " $s\left(k_{i}, k_{j}\right)$ " is between the upper and lower similarity thresholds " $s_{k u}$ " and " $s_{k l}$ " it indicates that the knowledge points " $k_{i}$ " and " $k_{j}$ " are highly similar but are not exactly the same. If the similarity 
TABLE 3: Similarity calculation method [28].

\begin{tabular}{lccc}
\hline Tree level position & Sense level position & Coefficient & Semantic similarity \\
\hline Not in the same word forest tree & None & $f$ & $s\left(k_{i}, k_{j}\right)=f$ \\
In the same word forest tree & Layer 2 branch & $a$ & $s\left(k_{i}, k_{j}\right)=a \times \cos (n \pi / 180) \times((n-m+1) / n)$ \\
In the same word forest tree & Layer 3 branch & $b$ & $s\left(k_{i}, k_{j}\right)=b \times \cos (n \pi / 180) \times((n-m+1) / n)$ \\
In the same word forest tree & Layer 4 branch & $c$ & $s\left(k_{i}, k_{j}\right)=c \times \cos (n \pi / 180) \times((n-m+1) / n)$ \\
In the same word forest tree & Layer 5 branch & $d$ & $s\left(k_{i}, k_{j}\right)=d \times \cos (n \pi / 180) \times((n-m+1) / n)$ \\
\hline
\end{tabular}

" $s\left(k_{i}, k_{j}\right)$ " is less than the lower similarity threshold " $s_{k l}$," it means that there is no semantic similarity and semantic relevance between the knowledge points " $k_{i}$ " and " $k_{j}$." If the similarity " $s\left(k_{i}, k_{j}\right)$ " is higher than the upper similarity threshold " $s_{k u}$," it shows that knowledge points " $k_{i}$ " and " $k_{j}$ " are the same. Furthermore, these two knowledge points will be combined as one knowledge point " $k$ " with the highest frequency weight, because the knowledge point with higher frequency weights means more likely to be hot knowledge points. The frequency, attention, and character weights of the merged knowledge point " $k$ " are equal to the sum of the frequency, attention, and character weights of these two knowledge points, respectively (Figure 6).

The similarity relationship set of knowledge points " $E_{K S}$ " and its weight set are expressed as

$$
\begin{array}{r}
E_{K S}=\left\{e_{k s}\left(k_{i}, k_{j}\right) \mid s_{k u} \geq s\left(k_{i}, k_{j}\right) \geq s_{k l}\right\}, \\
W\left(E_{K S}\right)=\left\{e_{k s}\left(k_{i}, k_{j}\right) \mid s_{k u} \geq s\left(k_{i}, k_{j}\right) \geq s_{k l}\right\} .
\end{array}
$$

3.3. Co-Creation Product Network Construction. To apply cocreation knowledge into product innovation effectively, this paper further constructs a co-creation product network to map with co-creation user and knowledge networks. Cocreation product network includes the nodes of product names and product feature network, shown in Figure 7. Based on the improved feature extraction and clustering [33] and a feature comparison network for competitiveness [34], this paper uses product features as nodes; uses attention and frequency of them as their weights; and uses co-occurrence, similarity, frequency comparison, and attention comparison relationships as four-dimensional edges to construct cocreation product feature network, shown in Figure 8. Besides, the nodes of product names are extracted and constructed with their weights of frequency and attention. And the mapping relationship between the nodes of product names and product feature network is constructed. The nodes of product names are used as the indexes to manage and analyse the information of every product's product features, so that the product feature networks belonged to every product can be constructed into a systematic product network.

Hence, the co-creation product network is expressed as

$$
G_{P}=\left(P, F, E_{F}, E_{P-F}, Q(P), H(P), Q(F), H(F), W\left(E_{F}\right)\right),
$$
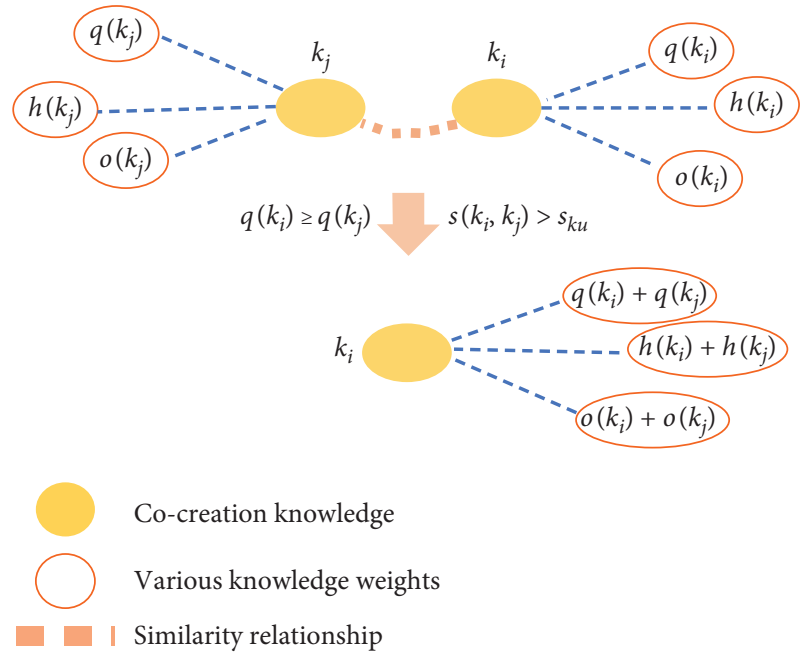

FIGURE 6: Knowledge points merging process.

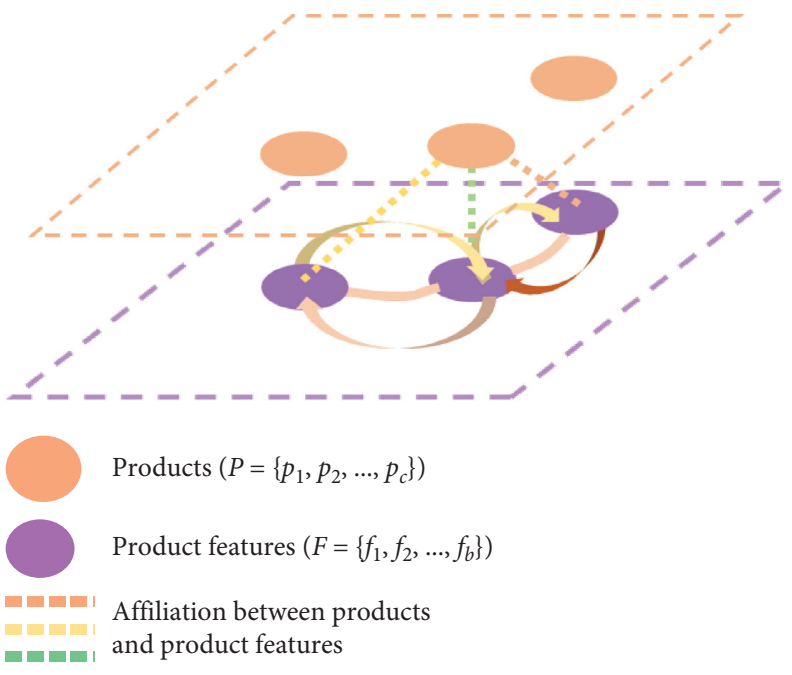

Figure 7: Co-creation product network.

where " $P$ " is the product set with frequency weight set " $Q(P)$ " and attention weight set " $H(P)$." " $F$ " is the product feature set with frequency weight set " $Q(F)$ " and attention weight set " $H(F)$." " $E_{F}$ " is product feature relationship set with weight set " $W\left(E_{F}\right)$." And " $E_{P-F}$ " is the product-toproduct feature mapping relationship set.

The product set and product feature set with various weight sets and the product feature relationship sets are constructed, respectively, in detail as follows: 

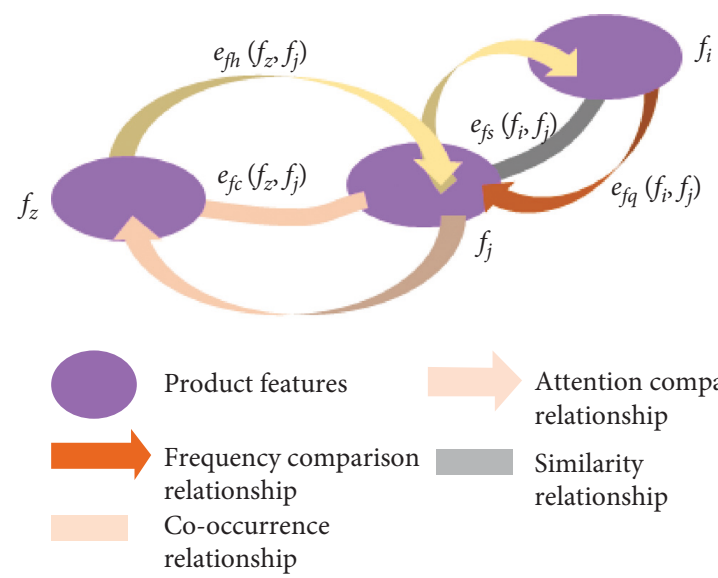

Attention comparison relationship

Similarity relationship relationship

FIgURE 8: Co-creation product feature network.

\subsubsection{The Weight Sets of Products and Product Features}

(1) The frequency weight set of product features " $Q(F)$ " is established based on their mentioned frequency, which is calculated similarly as formula (13).

(2) The attention weight set of product features " $H(F)$ " is established based on the browsing popularity and response heat of their carrier post, which is calculated similarly as formulas (10) and (11).

(3) The frequency weight set " $Q(P)$ " and attention weight set " $H(P)$ " of products are established based on frequency weight set " $Q(F)$ " and attention weight set " $H(F)$ " of product features, respectively. They are calculated as

$$
\begin{aligned}
& q\left(p_{i}\right)=\sum_{j=1}^{b} q\left(f_{j}\right) \mu\left(p_{i}, f_{j}\right), \\
& h\left(p_{i}\right)=\sum_{j=1}^{b} h\left(f_{j}\right) \mu\left(p_{i}, f_{j}\right) .
\end{aligned}
$$

If the product feature " $f_{j}$ " belongs to the product " $p_{i}$," " $\mu\left(p_{i}, f_{j}\right)=1$ ”; otherwise, “ $\mu\left(p_{i}, f_{j}\right)=0$."

3.3.2. The Product Feature Relationship Set. The product feature relationship set " $E_{F}$ " includes co-occurrence relationship set " $E_{F C}$ " with weight set " $W\left(E_{F C}\right)$," similarity relationship set " $E_{F S}$ " with weight set " $W\left(E_{F S}\right)$," frequency comparison relationship set " $E_{F Q}$ " with weight set " $W\left(E_{F Q}\right)$ " and attention comparison relationship set " $E_{F H}$ " with weight set " $W\left(E_{F H}\right)$ " and elaborated as follows.

(1) The co-occurrence relationship set of product feature " $E_{F C}$ " is established based on the co-occurrence of product feature. If the co-occurrence frequency " $w\left(f_{i}, f_{j}\right)$ " between two product features is not less than " $w_{f c}$," a co-occurrence relationship is constructed between them. And the co-occurrence relationship set of product features " $E_{F C}$ " and its weight set are expressed as

$$
\begin{aligned}
E_{F C} & =\left\{e_{f_{c}}\left(f_{i}, f_{j}\right) \mid w\left(f_{i}, f_{j}\right) \geq w_{f c}\right\}, \\
W\left(E_{F C}\right) & =\left\{w\left(f_{i}, f_{j}\right) \mid w\left(f_{i}, f_{j}\right) \geq w_{f c}\right\} .
\end{aligned}
$$

(2) The similarity relationship set of product features " $E_{F S}$ " is established based on the similarity " $s\left(f_{i}, f_{\mathrm{j}}\right)$ " between product features calculated by the words similarity algorithm based on Tongyici Cilin [33] similarly as the similarity relationship set of knowledge points. The similarity relationship set of product features " $E_{F S}$ " and its weight set are expressed as

$$
\begin{aligned}
E_{F S} & =\left\{e_{f s}\left(f_{i}, f_{j}\right) \mid s_{f u} \geq s\left(f_{i}, f_{j}\right) \geq s_{f l}\right\}, \\
W\left(E_{F S}\right) & =\left\{s\left(f_{i}, f_{j}\right) \mid s_{f u} \geq s\left(f_{i}, f_{j}\right) \geq s_{f l}\right\} .
\end{aligned}
$$

(3) The frequency comparison relationship set " $E_{F Q}$ " and the attention comparison relationship set " $E_{F H}$ " of product features are established based on the comparison of the product feature's mentioned frequency and attention. If the mentioned frequency of the product feature " $f_{i}$ " is higher than that of " $f_{j}$ ", a frequency comparison relationship " $e_{f q}\left(f_{i}, f_{j}\right)$ " is constructed from " $f_{i}$ " to " $f_{j}$." Similarly, if the attention of the product feature " $f_{i}$ " is higher than that of " $f_{j}$ ", an attention comparison relationship " $e_{f h}\left(f_{i}, f_{j}\right)$ " is constructed from " $f_{i}$ " to " $f_{j}$."

Finally, product features are mapped with products based on which product section the product features are extracted from. And the co-creation product network is constructed.

3.4. Analysis of the Mapping Relationships among Subnetworks. After the construction of the three subnetworks, the mapping relationships among them need to be established to complete the whole cyberspace.

\subsubsection{Co-Creation User Network and Co-Creation Knowledge} Network. The mapping relationship between co-creation user network and knowledge network, shown in Figure 9, is established based on if (1) users' focused post contains knowledge point keywords, or (2) knowledge point keywords are mentioned when users post or comment. If yes, a mapping relationship is constructed between the co-creation user " $u_{i}$ " and the co-creation knowledge point " $k_{j}$," " $\chi\left(u_{i}, k_{j}\right)=1$." And the weight of this mapping relationship is established based on its frequency. Therefore, the mapping 


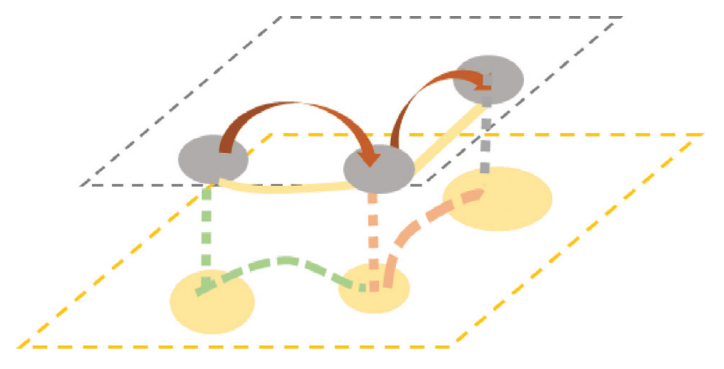

Co-creation users $\left(U=\left\{u_{1}, u_{2}, \ldots, u_{m}\right\}\right)$

Co-knowledge $\left(K=\left\{k_{1}, k_{2}, \ldots, k_{n}\right\}\right)$

므믄

FIGURE 9: Co-creation user network-knowledge network mapping relationship.

relationship set " $E_{U-K}$ " between co-creation users and knowledge and its weight set " $W\left(E_{U-K}\right)$ ")are expressed as

$$
\begin{aligned}
E_{U-K} & =\left\{e_{u-k}\left(u_{i}, k_{j}\right) \mid \chi\left(u_{i}, k_{j}\right)=1\right\}, \\
W\left(E_{U-K}\right) & =\left(w\left(u_{i}, k_{j}\right) \mid \chi\left(u_{i}, k_{j}\right)=1\right) .
\end{aligned}
$$

\subsubsection{Co-Creation Users Network and Co-Creation Product} Network. The mapping relationship between co-creation user network and product network, shown in Figure 10, is established based on if (1) product names or product features are mentioned in the text data generated by co-creation users, or (2) co-creation users' generated behaviour data such as attention, forwarding, reply, and comment mention product names or product features. If yes, a mapping relationship is constructed between the co-creation user " $u_{i}$ " and the co-creation product feature " $f_{j}$," " $\alpha\left(u_{i}, f_{j}\right)=1$." And the weight of this mapping relationship is established based on its frequency. Therefore, the mapping relationship set " $E_{U-F}$ " between co-creation users and product feature and its weight set " $W\left(E_{U-F}\right)$ " are expressed as

$$
\begin{aligned}
E_{U-F} & =\left\{e_{u-f}\left(u_{i}, f_{j}\right) \mid \alpha\left(u_{i}, f_{j}\right)=1\right\}, \\
W\left(E_{U-F}\right) & =\left(w\left(u_{i}, f_{j}\right) \mid \alpha\left(u_{i}, f_{j}\right)=1\right) .
\end{aligned}
$$

\subsubsection{Co-Creation Product Network and Co-Creation} Knowledge Network. The mapping relationship between cocreation product network and knowledge network, shown in Figure 11, is established based on the affiliation relationship between co-creation knowledge and product features. If yes, a mapping relationship is constructed between the co-creation product feature " $f_{i}$ " and the co-creation knowledge point " $k_{j}$," " $\beta\left(f_{i}, k_{j}\right)=1$." Therefore, the mapping relationship set " $E_{F-K}$ " between co-creation product feature and knowledge and its weight set " $W\left(E_{F-K}\right)$ ")are expressed as

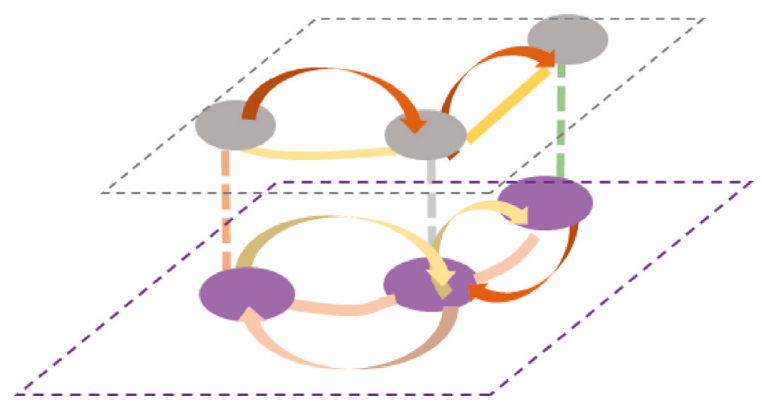

Co-creation users $\left(U=\left\{u_{1}, u_{2}, \ldots, u_{m}\right\}\right)$

Product features $\left(F=\left\{f_{1}, f_{2}, \ldots, f_{b}\right\}\right)$

는

FIGURE 10: User network-product network mapping relationship.

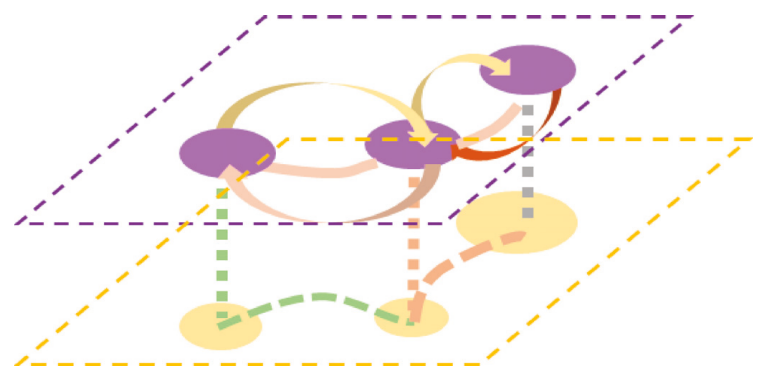

Product features $\left(F=\left\{f_{1}, f_{2}, \ldots, f_{b}\right\}\right)$

Co-creation knowledge $\left(K=\left\{k_{1}, k_{2}, \ldots, k_{n}\right\}\right)$

Product features-knowledge mapping relationship

FIgURE 11: Product network-knowledge network mapping relationship.

$$
\begin{aligned}
E_{F-K} & =\left\{e_{f-k}\left(f_{i}, k_{j}\right) \mid \beta\left(f_{i}, k_{j}\right)=1\right\}, \\
W\left(E_{F-K}\right) & =\left\{w\left(f_{i}, k_{j}\right) \mid \beta\left(f_{i}, k_{j}\right)=1\right\} .
\end{aligned}
$$

\section{Case Study}

The focus of this study is to add some important but neglected relationships, weights, and dimension to make the previous co-creation network more comprehensive. Accordingly, the reasons why mentioned elements are necessary to be considered in the construction of co-creation knowledge cyberspace have been clearly explained in the literature review. Thus, in this section, we do not want to prove the priority of our model but only to prove the usability and application of the model in one case study. Therefore, this paper selects the MIUI community of Xiaomi enterprise as an application example. It is a well-known cocreation community with more than 1900 million registered users in China. MIUI community focuses on the customergenerated content on their products and allows its registered 


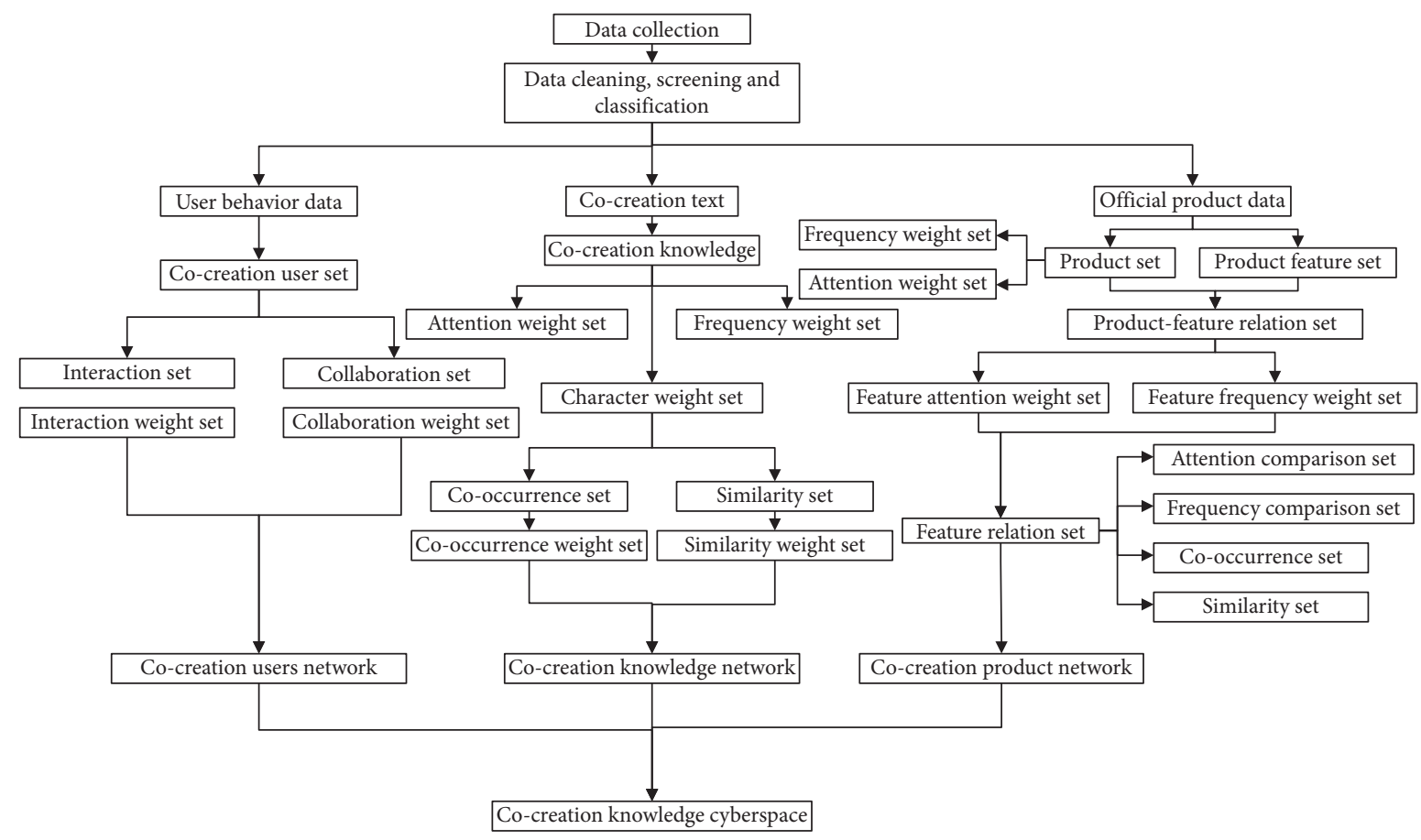

FIgURE 12: Case study application analysis flow chart.

users to establish their own personal homepages. All registered users may contact each other through favouring, sharing, and commenting on valuable content. As it generates a large amount of interactive data and text data every day, MIUI community is a suitable analytical case for this model. The application analysis process is shown in Figure 12.

First, this paper uses "Octopus" collector to collect post data in Red Rice Note 5/5A/4X panel on March 17th, 2018, excluding the useless and repetitive posts, and the posts with the browsing number less than 300 . Three types of data per post are collected as follows:

(1) Co-creation user behaviour data, including post author ID, reviewer ID, post browsing number, and comment number

(2) Co-creation text data, including post titles, text, and comments

(3) Official product data, including product list and text data posted by the official operation team

Then, python's jieba segmentation toolkit and nltk natural language processing toolkit are used to process the text data. And the three subnetworks are constructed respectively according to the collected and processed data. Finally, the co-creation cyberspace is integrated for Xiaomi enterprise to support its user management, knowledge management, and product innovation.

4.1. Co-Creation User Network Construction. For co-creation user network construction, this study first encodes the user IDs in MIUI community by establishing a co-creation user set " $U=\left\{u_{1}, u_{2}, \ldots, u_{184}\right\}$ " and then uses the excel software to screen the collaboration and interaction relationships among users that occur no less than two times. According to Section 3.1, a collaboration relationship set of co-creation users " $E_{U D}=\left\{e_{u d 1}, e_{u d 2}, \ldots, e_{u d 396}\right\}$ " with its weight set " $W\left(E_{U D}\right)$ " and an interaction relationship set of co-creation users " $E_{U A}=\left\{e_{u a 1}, e_{u a 2}, \ldots, e_{\text {ua } 3590}\right\}$ " with its weight set "W( $\left(E_{U A}\right)$ " can be obtained. Besides, co-creation users are ranked by the node degree in descending order and the cocreation users with top 60 node degree as shown in Table 4 .

The co-creation user network is visualized by Gephi 0.9 .2 software in Figure 13. The Fruchterman Reingold algorithm in the Gephi layout function was used to rearrange the network, and Gephi's own community detection algorithm was used to group the main nodes where the size of the node is proportional to the size of the node degree. This means that the larger the user node is, the larger the degree is. Meanwhile, if the node is closer to the centre, the behaviour of the user has more social influence and importance. In this visualized co-creation user network, "U108" is the largest user node, indicating that he interacts with other users the most. Besides, "U108" is in the centre of the co-creation user network, meaning that he has a lot of influence over other users. Therefore, "U108" obviously is the opinion leaders. Xiaomi enterprise needs to pay more attention to him, taking incentives to encourage him to improve his innovation rate and taking advantage of his big influence to motivate other users to co-create as well. Similarly, "U109" and "U61" are the users that Xiaomi enterprise needs to pay more attention to. Moreover, in the visualized co-creation network, user nodes with the same colour mean that these users have closer social relationships. The users are divided into small groups so that Xiaomi enterprise can manage them more effectively based on the character of each group. 
TABle 4: The users with top 60 node degree in co-creation user network.

\begin{tabular}{|c|c|c|}
\hline Rank & User ID & Node degree \\
\hline 1 & U108 & 390 \\
\hline 2 & U109 & 42 \\
\hline 3 & U61 & 38 \\
\hline 4 & $\mathrm{U} 2$ & 33 \\
\hline 5 & $\mathrm{U} 3$ & 32 \\
\hline 6 & $\mathrm{U} 28$ & 29 \\
\hline 7 & U154 & 24 \\
\hline 8 & U158 & 23 \\
\hline 9 & U145 & 21 \\
\hline 10 & $\mathrm{U} 26$ & 20 \\
\hline 11 & U69 & 18 \\
\hline 12 & U82 & 18 \\
\hline 13 & U115 & 18 \\
\hline 14 & U130 & 18 \\
\hline 15 & U144 & 18 \\
\hline 16 & U94 & 17 \\
\hline 17 & U101 & 17 \\
\hline 18 & U75 & 16 \\
\hline 19 & U168 & 16 \\
\hline 20 & U72 & 15 \\
\hline 21 & U105 & 15 \\
\hline 22 & U122 & 15 \\
\hline 23 & U137 & 15 \\
\hline 24 & U151 & 15 \\
\hline 25 & U138 & 14 \\
\hline 26 & U22 & 13 \\
\hline 27 & U51 & 13 \\
\hline 28 & U139 & 12 \\
\hline 29 & U6 & 11 \\
\hline 30 & U8 & 11 \\
\hline 31 & U9 & 11 \\
\hline 32 & U32 & 11 \\
\hline 33 & U157 & 11 \\
\hline 34 & U19 & 10 \\
\hline 35 & U41 & 10 \\
\hline 36 & U83 & 10 \\
\hline 37 & U146 & 10 \\
\hline 38 & U165 & 10 \\
\hline 39 & U177 & 10 \\
\hline 40 & U53 & 9 \\
\hline 41 & U73 & 9 \\
\hline 42 & U76 & 9 \\
\hline 43 & U135 & 9 \\
\hline 44 & U143 & 9 \\
\hline 45 & U14 & 8 \\
\hline 46 & U42 & 8 \\
\hline 47 & U92 & 8 \\
\hline 48 & U97 & 8 \\
\hline 49 & U103 & 8 \\
\hline 50 & U111 & 8 \\
\hline 51 & U113 & 8 \\
\hline 52 & U123 & 8 \\
\hline 53 & U181 & 8 \\
\hline 54 & U25 & 7 \\
\hline 55 & U30 & 7 \\
\hline 56 & U58 & 7 \\
\hline 57 & U74 & 7 \\
\hline 58 & U129 & 7 \\
\hline 59 & U147 & 7 \\
\hline 60 & U38 & 6 \\
\hline
\end{tabular}

4.2. Co-Creation Knowledge Network Construction. For cocreation knowledge network construction, this study first uses HIT pyltp, jieba segmentation, and natural language tools in python to perform sentence segmentation, word segmentation, part-of-speech tagging, and word frequency statistics on the text content of posts. Then, with the calculation of frequency weight, attention weight, and character weight for knowledge point keywords, a preliminary knowledge points set and its weight set can be obtained. The extracted knowledge point keywords with top 15 frequency weights are shown in Table 5 with their attention weight and character weight.

In Table 5 , "Note $5 \mathrm{~A}$ " is the keyword with the largest frequency weight, which means that it is the knowledge point keyword mentioned most by the community users. It also has a large attention weight, which means that it is the knowledge point keyword that many community users browsed and responded. Besides, it has large position weight, part-of-speech weight, and span weight as well, which means that it is an important keyword of the posts. Similarly, "Fans," "System," Battery," and "Screen" are the knowledge point keywords with large weights.

In addition, this study uses the HIT University pyltp Tongyici Cilin expansion to calculate the similarity of keywords and merges highly similar knowledge points to obtain a revised set of co-creation knowledge points. Meanwhile, knowledge point weight set and knowledge cooccurrence relationship are reorganized, and a similar relationship set of knowledge points is constructed. Some synonymous knowledge point keywords are shown in Table 6, and the merged knowledge point keywords and their weights are shown in Table 7 . The reason for use of Chinese in Table 6 is that some of the translation of knowledge point 1 and knowledge point 2 is the same words in English, while these two words and their intended meaning is different in China.

After synonymous knowledge point keyword merging, Table 7 shows that "Photography" is the merged knowledge point keyword with the largest frequency weight and character weight, which shows different results compared with Table 5. Therefore, it proves that repetitiveness and similarity among knowledge points would disturb hot knowledge discovery.

The co-creation knowledge network is visualized by Gephi 0.9.2 software in Figure 14 and the Fruchterman Reingold algorithm in the Gephi layout function is used to rearrange the network. Hence, the knowledge nodes are clustered and divided using Gephi's own community detection algorithm, where the size of the knowledge node is proportional to its weights. The names of nodes are automatically generated by Gephi software based on the Chinese posts data collected in MIUI community, and they are translated into English for better understanding. The larger the knowledge node is, the larger the weight it has and the more the concern it receives from the users in the co-creation community. And the closer the knowledge node is to the centre of the network, the more important is this knowledge point for the users. In the visualized co-creation knowledge network, "photography" is the largest knowledge 


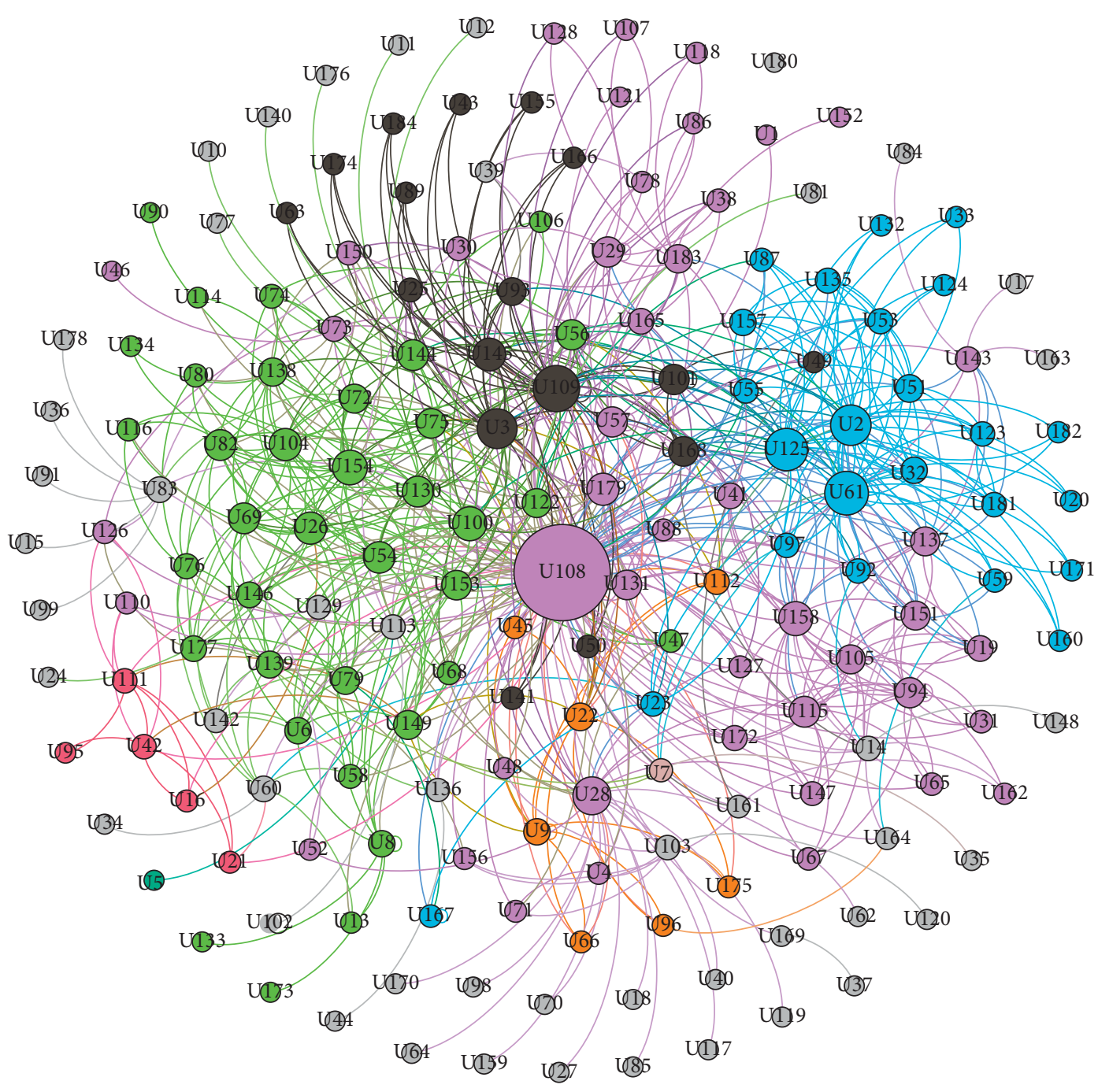

FIGURE 13: Visualized co-creation user network.

TABLE 5: The extracted knowledge point keywords with top 15 frequency weight and their various weights.

\begin{tabular}{|c|c|c|c|c|c|}
\hline \multirow{2}{*}{ Keywords } & \multirow{2}{*}{ Frequency weight } & \multirow{2}{*}{ Attention weight } & \multicolumn{3}{|c|}{ Character weight } \\
\hline & & & Position weight & Part-of-speech weight & Span weight \\
\hline Note $5 \mathrm{~A}$ & 80 & $3.51817 E+11$ & 78.6 & 1 & 75.33333 \\
\hline Fans & 37 & $3.51817 E+11$ & 5.4 & 1 & 3 \\
\hline Purchase & 32 & 1581825.91 & 2.6 & 0.6 & 1.333333 \\
\hline Discount & 30 & 1581787.063 & 0 & 0.6 & 0 \\
\hline System & 19 & 1581326.577 & 6.4 & 1 & 3.333333 \\
\hline Battery & 16 & $3.51817 E+11$ & 7 & 1 & 3.333333 \\
\hline Use & 15 & 1081.948809 & 7.6 & 0.6 & 4.333333 \\
\hline Edition & 15 & 1160.523897 & 5.2 & 1 & 2.666667 \\
\hline Screen & 15 & $3.51817 E+11$ & 6 & 1 & 3.333333 \\
\hline Software & 13 & 1581226.719 & 4.2 & 1 & 2.333333 \\
\hline Express & 13 & 705.2475923 & 5.2 & 0.6 & 2.333333 \\
\hline Wakeup & 12 & 655.3813314 & 6.8 & 0.6 & 3.666667 \\
\hline Settings & 12 & 679.439974 & 2.4 & 0.6 & 1.333333 \\
\hline Mode & 11 & 1580806.593 & 4.4 & 1 & 2.333333 \\
\hline WeChat & 10 & 1581228.874 & 1.8 & 1 & 1 \\
\hline
\end{tabular}

node, indicating that it is the knowledge point the users mostly concern about. Besides, "photography" knowledge point is in the centre of the green co-creation knowledge network, meaning that it is the core knowledge point connecting many other knowledge points, so that it is a very important knowledge point for product innovation. 
TABLE 6: Example of some synonymous knowledge point keywords.

\begin{tabular}{lcc}
\hline Similarity & Knowledge point 1 & Knowledge point 2 \\
\hline 1 & Photography & Photograph \\
1 & Price & Value \\
1 & Earphone & Machine \\
1 & Phone & Inexpensive \\
1 & Cheap & Perfect \\
1 & Beautiful & Wonderful \\
1 & Beautiful & Information \\
1 & Message & .
\end{tabular}

TABLE 7: Example of the merged knowledge point keywords and their weights.

\begin{tabular}{lccccc}
\hline Knowledge points & Frequency weight & Attention weight & $\begin{array}{c}\text { Knowledge points } \\
\text { Position weight }\end{array}$ & $\begin{array}{c}\text { Part-of-speech weight } \\
\text { Span weight }\end{array}$ \\
\hline Photography & 28.00 & 86.49 & 26.00 & 23.60 & 24.00 \\
Price & 9.00 & 351814930895.95 & 1.20 & 2.00 & 2.00 \\
Earphone & 9.00 & 790.28 & 3.20 & 2.00 & 1.33 \\
Phone & 10.00 & 836.29 & 3.00 & 1.20 & 0.33 \\
Cheap & 6.00 & 351816511887.58 & 0.60 & 14.60 & 13.67 \\
Beautiful & 18.00 & 351814930835.20 & 14.20 & 2.00 & 1.33 \\
Message & 5.00 & 65.89 & 2.40 & & \\
\hline
\end{tabular}

Similarly, the knowledge point nodes such as "cost-performance," "screen", "battery" and "storage" are larger, and therefore, Xiaomi enterprise should focus more on these knowledge points to do product innovation. Furthermore, in the visualized co-creation knowledge network, knowledge point nodes with the same colour mean that these knowledge points have closer co-occurrence and similar relationships. The knowledge points are divided into small groups so that Xiaomi enterprise can manage the co-creation knowledge more effectively.

4.3. Co-Creation Product Network Construction. For cocreation product network construction, this study extracts and filters product names from the product list and then obtains the product name set. The frequently mentioned product features are extracted from the post text based on the improved Apriori algorithm and the preliminary product feature set is obtained with PMI thresholds. Then, similar to the relevant calculation indexes of the co-creation knowledge network, this study (1) calculates the frequency weight and attention weight of each product feature keyword as shown in Table 8, (2) calculates the similarity among product feature keywords based on Tongyici Cilin, and (3) finally merges synonymous product feature keywords and reconstructs the product feature set.

In Table 8, "Price," "Edition," "Function," "CNC," and "CPU" are the product features with large frequency and attention weights, which means that these are the product features the community users most mentioned, browsed, and responded. Therefore, Xiaomi enterprise should pay more attention to these product features for product innovation.

The co-creation product network is visualized by Gephi 0.9.2 software in Figure 15. As illustrated, like the co- creation knowledge network, the product feature node size is proportional to the various weights of the nodes. However, the names of nodes are automatically generated by Gephi software based on the Chinese posts data collected in MIUI community, and they are translated into English for better understanding. The larger the product feature node is, the larger the weight it has and the more the concern it receives from the users in the co-creation community. And the closer the product feature node is to the centre of the network, the more important is this product feature for the users. In the visualized co-creation product network, "DPI," "two-core," "module," and "light" are the nodes near the centre of the network, indicating that they are the important product features the users most concern. Therefore, Xiaomi enterprise should pay more attention to these product features and mine the relevant knowledge for product innovation. Furthermore, in the visualized co-creation product network, product feature nodes with the same colour mean that these product features have closer co-occurrence and similar relationships. The product features are divided into small groups so that Xiaomi enterprise can manage these product features more effectively.

4.4. Construction of Co-Creation Cyberspace Model for Product Innovation. Finally, by counting the mentioned frequency of keywords that each user of the co-creation user set posted, focused, forwarded, replied, and commented, this study constructs the mapping relationship set between the co-creation user network and co-creation knowledge network, and the mapping relationship set between the cocreation user network and co-creation product network, respectively. Besides, considering the affiliation relationship between co-creation knowledge and product features, a mapping relationship set between co-creation knowledge 


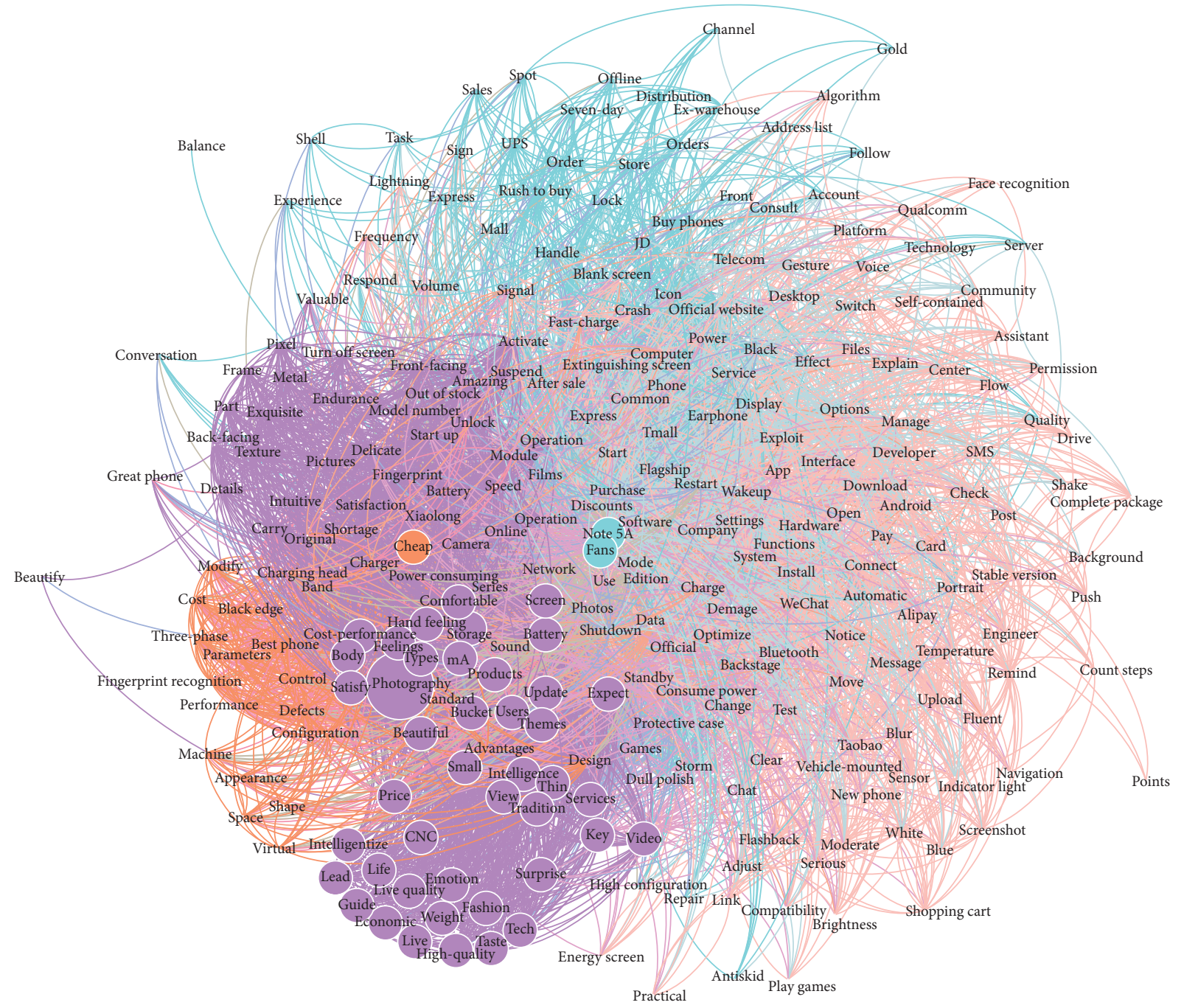

FIGURE 14: Visualized co-creation knowledge network.

TABLE 8: Example of some extracted product features and their weights.

\begin{tabular}{|c|c|c|c|c|c|}
\hline Product features & Frequency weight & Attention weight & Product features & Frequency weight & Attention weight \\
\hline Price & 59 & 756462.7 & Data & 4 & 31118.08 \\
\hline Edition & 18 & 378954.4 & Games & 3 & 31109.38 \\
\hline Function & 21 & 349008.8 & Positioning & 3 & 31109.38 \\
\hline $\mathrm{CNC}$ & 10 & 348859.6 & Great phone & 3 & 31094.95 \\
\hline CPU & 8 & 348768.9 & Reduce price & 5 & 30995.03 \\
\hline Brand & 4 & 347274.6 & Capacity & 5 & 30995.03 \\
\hline Playing games & 3 & 347097.1 & Platform & 5 & 30995.03 \\
\hline Phone & 2 & 347097.1 & Dual channel & 5 & 30995.03 \\
\hline Low version & 1 & 347097.1 & Price difference & 5 & 30995.03 \\
\hline Test data & 1 & 347097.1 & Button & 5 & 30995.03 \\
\hline Option & 2 & 144088 & Screen & 5 & 30995.03 \\
\hline Fingerprint & 6 & 144082.7 & Gesture & 5 & 30995.03 \\
\hline Camera & 15 & 32873.97 & System & 5 & 30995.03 \\
\hline Storage & 16 & 32603.31 & Cost & 5 & 30995.03 \\
\hline Performance & 14 & 31401.37 & Front-facing & 5 & 30995.03 \\
\hline
\end{tabular}

network and co-creation product network is constructed. The integrated construction of co-creation knowledge network cyberspace model for product innovation is visualized in Figure 16.
In Figure 16, the co-creation users, knowledge, products, and product features are connected together in the integrated cyberspace model. Again, as we used Chinese posts data collected in MIUI community, the names are 


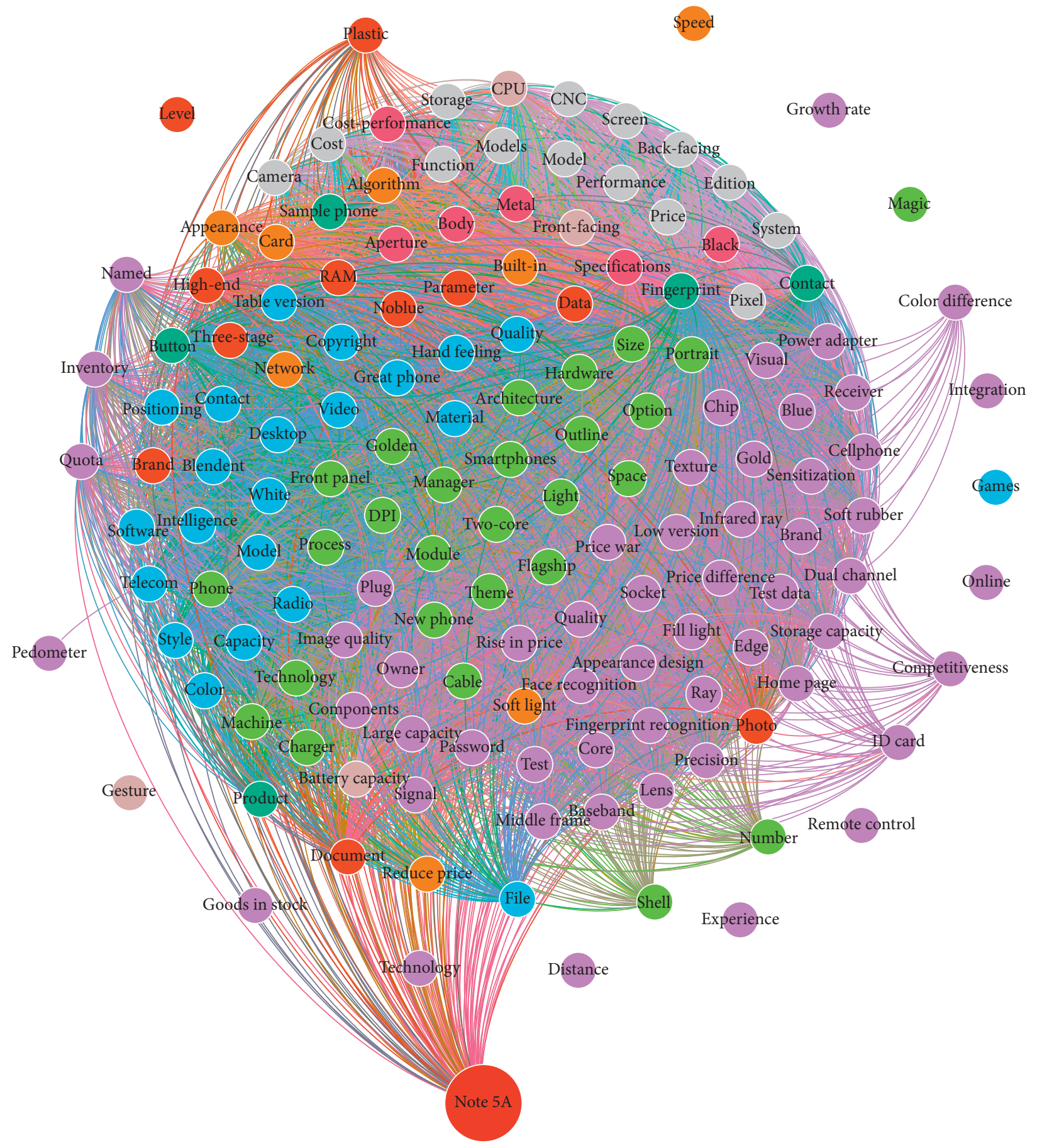

Figure 15: Visualized co-creation product network.

automatically generated by Gephi software in Chinese and they are translated into English for better understanding. The grey nodes represent co-creation users, the apricot nodes represent co-creation knowledge, the purple nodes represent co-creation product features and the orange node represents the co-creation product. In this integrated model, co-creation knowledge and its related users, products, and product features can be managed systematically and the cocreation knowledge of each user and each product can be traced, respectively. Therefore, Xiaomi enterprise can do product innovation according to the relevant co-creation knowledge of the focused product and motivate the corresponding users to co-create actively in the MIUI community. For example, if Xiaomi enterprise wants to do some product innovation in Red Rice Note 5A mobile phone's "performance," it should focus on the product feature "performance" connected co-creation knowledge "Xiaolong" and try to motivate the co-creation users who connect to "Xiaolong," such as the users "U151" and "U94," to cocreate more actively. 


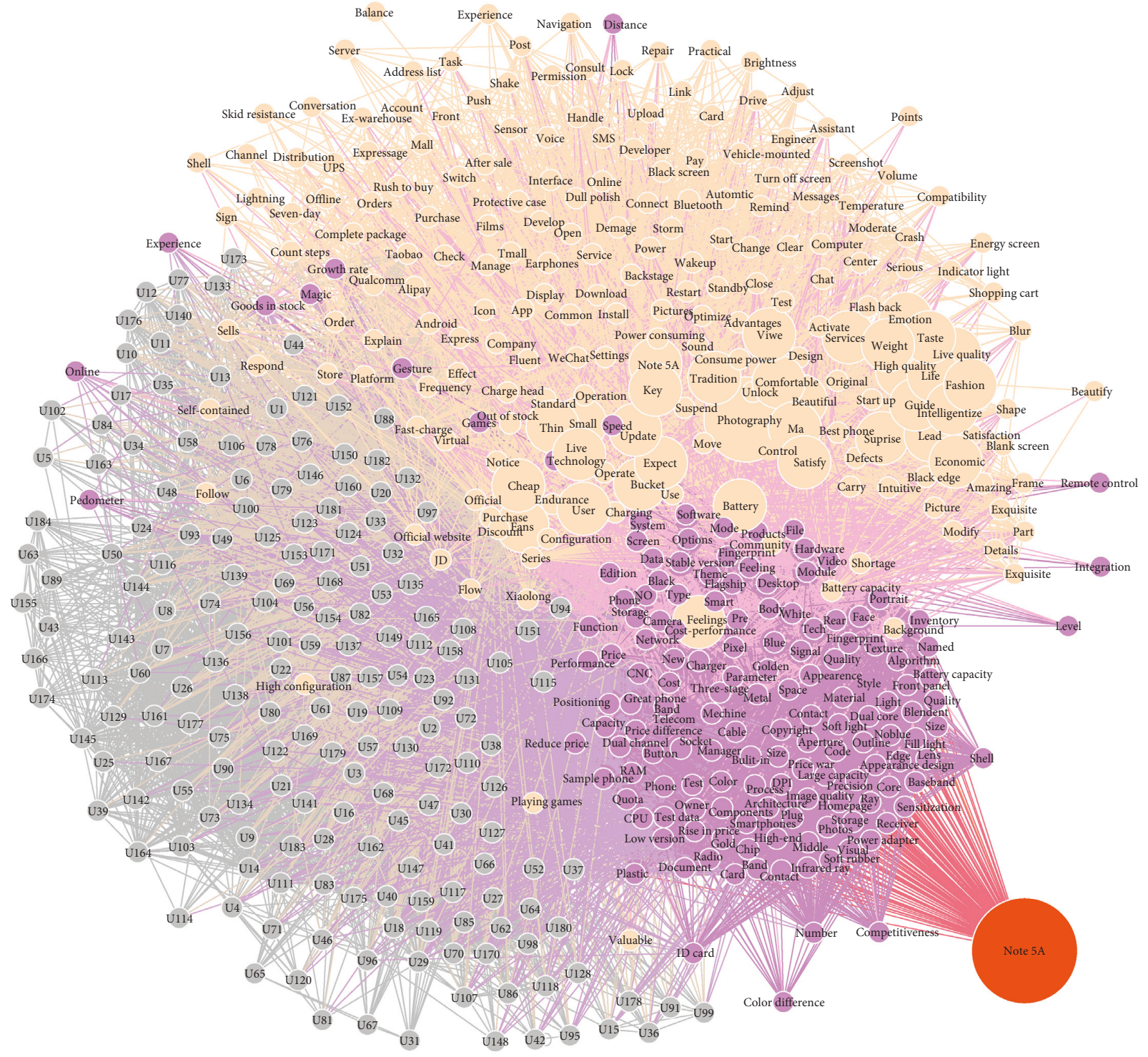

FIGURE 16: Visualized co-creation cyberspace model for product innovation.

\section{Discussion and Conclusion}

Several existing research studies have shown great importance of knowledge management and application during product innovation in co-creation community. However, most of the existing research studies only considered cocreation user and knowledge network, failing to map cocreation knowledge with product innovation accurately. Besides, when constructing each co-creation network, the weights and relationships of users and knowledge were not considered comprehensively. Therefore, this paper constructs a "user-knowledge-product" co-creation cyberspace super-network model to address these limitations. The contribution to theory and industry and the limitations of this paper are discussed in detail as follows.

5.1. Contribution to Theory. Aiming at the limitations of the existing research, this paper contributes to the theory from three different perspectives comparing with relevant literature, shown in Table 9. First, for better co-creation user management, the cocreation user network is improved by further considering the interaction relationship among co-creation users. Both the collaboration network caused by social choice and the interaction network caused by social influence are constructed. Second, a comprehensive co-creation knowledge network further considering the similarity relationship and the character weights is constructed to avoid information overload and make hot co-creation knowledge identification more accurate. Third, the two-tier co-creation networks are expanded by constructing a co-creation product network to map with each of them for more effective product innovation. Moreover, the co-creation users, knowledge, and products are integrated into a co-creation cyberspace super-network model for systematic management.

5.2. Contribution to Industry. A well-known co-creation community in China is selected as a case to verify the 
TABle 9: Comparison with relevant literature.

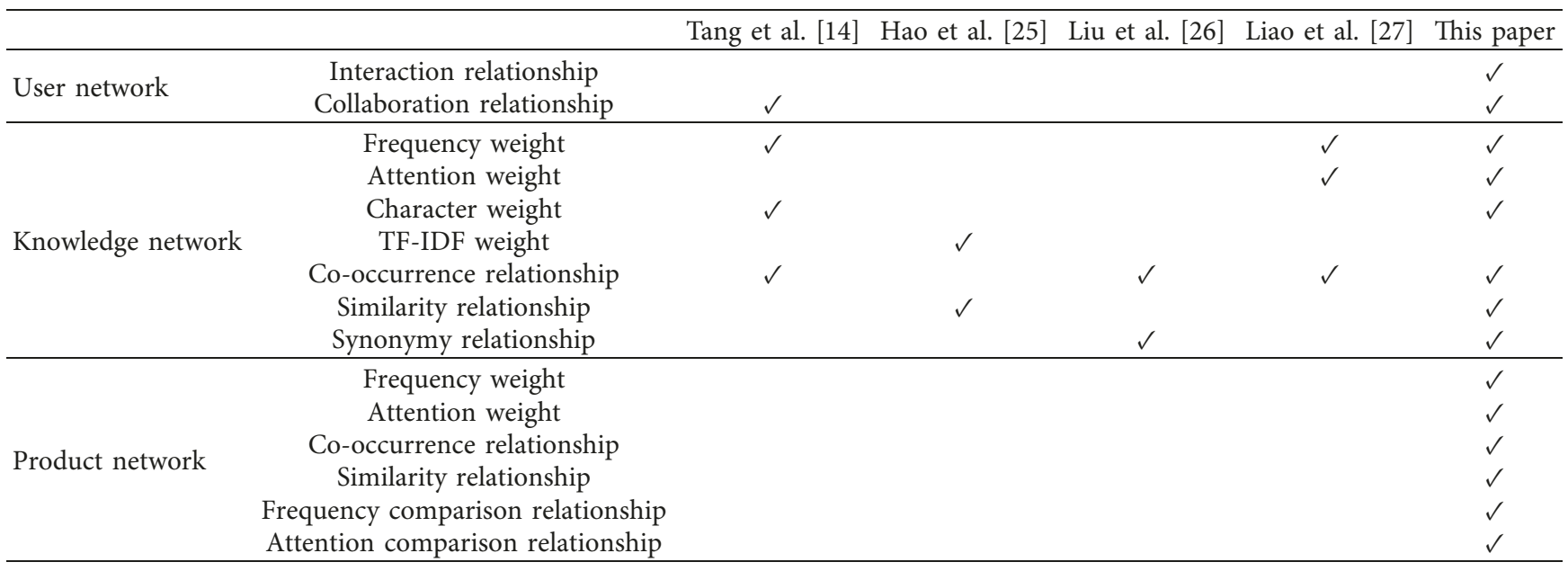

feasibility and validity of the proposed co-creation cyberspace super-network model. The proposed model can provide enterprises with a more comprehensive and detailed integration framework for user discovery, knowledge mining, and application for product innovation in co-creation communities. Through identifying leading users and hot knowledge together with product features, enterprises can:

(1) Grasp the prevailing customer needs and expectations of the consuming products and respond to these needs in time with proper quality for higher customer satisfaction.

(2) Involve customers in product development and improvement process and benefit from their innovation knowledge in the form of ideas, suggestions, and solutions about their consuming products. However, customer involvement can reduce the time and resources as the product innovation and ideation is outsourced to the leading users who may be the best resource to perform this task.

(3) Eliminate the unnecessary and unpopular products from the market based on the received real data from the customers; which will lead to a significant reduction in product/process complexity and cost saving.

(4) Build a dynamic innovation knowledge basement and forecast hotspot trend to gain the initiative in products or service design.

5.3. Limitations of the Study and Threats to Validity. The scope of this study only explained why those important but neglected relationships, weights, and dimension were necessary based on the related literature and used a case study to prove the usability of our proposed model. However, a comparative analysis in order to prove the priority of our model worth investing further in future projects of this nature. Moreover, a separate study to compare and report other available methods of co-creation network construction should be considered in the future. Besides, due to the limitation of time and resources when constructing the cocreation cyberspace, this paper does not consider its dynamic evolution with time. In the future, the dynamic research of network and the use of dynamic network indicators will be applied to this model after further research. Furthermore, in the co-creation community, usergenerated context is not only in the form of text, but also in the form of pictures, links, and videos. Future study could take various types of user-generated content into account to mine co-creation knowledge comprehensively. Finally, this paper collected data only from MIUI community and only considered the text in the form of Chinese. It would be interesting to consider replicating this study with other cocreation communities under different language backgrounds.

\section{Data Availability}

The data used to support the findings of this study are available from the corresponding author upon request.

\section{Disclosure}

Any opinions, findings, conclusions, or recommendations expressed in this paper are those of the authors and do not necessarily reflect the views of the above funding agencies.

\section{Conflicts of Interest}

The authors declare that there are no conflicts of interest regarding the publication of this paper.

\section{Authors' Contributions}

$\mathrm{Yu}$ Wang was responsible for conceptualization, project administration, and supervision. Jiacong $\mathrm{Wu}$ performed formal analysis and reviewed, revised, and edited the article. $\mathrm{Ru}$ Zhang was responsible for methodology, data curation, and original draft of the manuscript. Sara Shafiee reviewed the manuscript. Cheng Li performed discussion and format editing. 


\section{Acknowledgments}

This research was partially supported by Jinan University, the National Natural Science Foundation of China under Grant nos. 71772075, 71302153, and 71672074, the Technology R\&D Foundation of Guangzhou, China, under Grant no. 201607010012, the Social Science Foundation of Guangzhou, China, under Grant no. 2018GZYB31, and the Foundation of Chinese Government Scholarship No. 201806785010.

\section{References}

[1] K. Kazadi, A. Lievens, and D. Mahr, "Stakeholder co-creation during the innovation process: identifying capabilities for knowledge creation among multiple stakeholders," Journal of Business Research, vol. 69, no. 2, pp. 525-540, 2016.

[2] E. Constantinides, L. A. Brünink, and C. L. Romero, "Customer motives and benefits for participating in online cocreation activities," International Journal of Internet Marketing and Advertising, vol. 9, no. 1, pp. 21-48, 2015.

[3] J. Q. Dong and W. Wu, "Business value of social media technologies: evidence from online user innovation communities," The Journal of Strategic Information Systems, vol. 24, no. 2, pp. 113-127, 2015.

[4] W. Guo, Q. Zheng, W. An, and W. Peng, "User roles and contributions during the new product development process in collaborative innovation communities," Applied Ergonomics, vol. 63, pp. 106-114, 2017.

[5] L. Bengtsson and N. Ryzhkova, "Managing a strategic source of innovation: online users," International Journal of Information Management, vol. 33, no. 4, pp. 655-662, 2013.

[6] S. Kamboj, B. Sarmah, S. Gupta, and Y. Dwivedi, "Examining branding co-creation in brand communities on social media: applying the paradigm of stimulus-organism-response," International Journal of Information Management, vol. 39, pp. 169-185, 2018.

[7] N. Zhang, Z.-M. Zhou, C.-T. Su, and N. Zhou, "How do different types of community commitment influence brand commitment? The mediation of brand attachment," Cyberpsychology, Behavior, and Social Networking, vol. 16, no. 11, pp. 836-842, 2013.

[8] N. Hajli, M. Shanmugam, S. Papagiannidis, D. Zahay, and M.-O. Richard, "Branding co-creation with members of online brand communities," Journal of Business Research, vol. 70, pp. 136-144, 2017.

[9] M. A. Irani, T. S. M. Z. bin Tan, and S. M. Ghazali, "Role of customer knowledge in developing new products and services," in Proceedings of the 2014 4th International Conference on Engineering Technology and Technopreneuship (ICE2T), pp. 6-9, IEEE, Kuala Lumpur, Malaysia, August 2014.

[10] Y. Ding, C. W. Phang, X. Lu, C. H. Tan, and J. Sutanto, "The role of marketer-and user-generated content in sustaining the growth of a social media brand community," in Proceedings of the 2014 47th Hawaii International Conference on System Sciences, pp. 1785-1792, IEEE, Waikoloa, Hawaii, January 2014.

[11] Y.-J. Chen and Y.-M. Chen, "Knowledge evolution course discovery in a professional virtual community," KnowledgeBased Systems, vol. 33, pp. 1-28, 2012.

[12] Y. Zhang, "Knowledge management model of virtual community based on knowledge intensive services," Information Science, vol. 4, pp. 25-28, 2015.
[13] X. F. Zhang, Y. Yang, and G. D. Yu, "Collaborative customer selection based on knowledge perspective," Computer Integrated Manufacturing System, vol. 11, pp. 2817-2826, 2015.

[14] H. T. Tang, Z. H. Li, and R. Qin, "Research on user and knowledge model of the mass collaborative," Chinese Journal of Management, vol. 6, pp. 859-867, 2017.

[15] T. Chen, Y. Shao, and Y. Han, "Collaborative innovation model research based on knowledge super-network and TRIZ," in LISS 2014, pp. 1169-1174, Springer, Berlin, Germany, 2015.

[16] K. Yang, Y. Li, Y. Xiong et al., "Knowledge driven product innovation design based on complex network," Computer Integrated Manufacturing System, vol. 9, pp. 2257-2269, 2015.

[17] A. A. Yassine and J. A. Bradley, "A knowledge-driven, network-based computational framework for product development systems," Journal of Computing and Information Science in Engineering, vol. 13, no. 1, Article ID 011005, 2013.

[18] M. Sheng and R. Hartono, "An exploratory study of knowledge creation and sharing in online community: a social capital perspective," Total Quality Management \& Business Excellence, vol. 26, no. 1-2, pp. 93-107, 2015.

[19] J. Swan, S. Newell, and M. Robertson, "Limits of IT-driven knowledge management initiatives for interactive innovation processes: towards a community-based approach," in Proceedings of the 33rd Annual Hawaii International Conference on System Sciences, p. 11, January 2000.

[20] E. Von Hippel, "Lead users: a source of novel product concepts," Management Science, vol. 32, no. 7, pp. 791-805, 1986.

[21] Y. S. Hau and M. Kang, "Extending lead user theory to users" innovation-related knowledge sharing in the online user community: the mediating roles of social capital and perceived behavioral control," International Journal of Information Management, vol. 36, no. 4, pp. 520-530, 2016.

[22] Y. S. Hau and Y.-G. Kim, "Why would online gamers share their innovation-conducive knowledge in the online game user community? Integrating individual motivations and social capital perspectives," Computers in Human Behavior, vol. 27, no. 2, pp. 956-970, 2011.

[23] J. Hafkesbrink and M. Schroll, "Ambidextrous organisational and individual competencies in oi: the dawn of A new research agenda," in Open Innovation: A Multifaceted Perspective: Part II, pp. 517-570, World Scientific, Singapore, 2016.

[24] P. K. P. Divakaran, "Community-aided brand concept maps: a new approach for eliciting brand association networks," in Proceedings of the 2014 8th International Days of Statistics and Economics Conference, pp. 1208-1217, Prague, Czech Republic, September 2014.

[25] J. Hao, Y. Yan, G. X. Wang et al., "LSA-based domain knowledge map construction method," Transactions of Beijing Institute of Technology, vol. 7, pp. 691-694, 2014.

[26] J. Liu, H. B. Xu, H. F. Tang et al., "Model and construction method on dynamic knowledge network in big data," Journal of Computer Research and Development, vol. 2, pp. 86-93, 2014.

[27] X. Liao, Z. H. Li, and Y. J. Xi, "Modeling and analyzing methods of user-innovation knowledge in enterprise communities based on weighted knowledge network," Systems Engineering-Theory \& Practice, vol. 1, pp. 94-105, 2016.

[28] F. Y. Wang and Q. Shao, "Co-word analysis combining the WK and CSK co-word models," University of Electronic Science and Technology of China, vol. 2, pp. 110-113, 2017.

[29] Y. Wang, J. Wu, R. Zhang, and C. Li, "The construction of "user-knowledge-product" co-creation knowledge cyberspace 
served for product innovation," in Proceedings of the 201911 th CIRP Conference on Industrial Product-Service Systems, vol. 83, pp. 467-472, Hong Kong, China, May 2019.

[30] J. He and Y. Z. Liu, "Research on online social networks link prediction based on multidimensional social relations," Journal of Modern Information, vol. 7, pp. 41-46, 2017.

[31] L. Ma, R. Krishnan, and A. L. Montgomery, "Latent homophily or social influence? An empirical analysis of purchase within a social network," Management Science, vol. 61, no. 2, pp. 454-473, 2015.

[32] R. Barbosa and R. Santos, "Multidimensional approach to online interest networks," DEStech Transactions on Computer Science and Engineering, 2016.

[33] C. B. Li, C. P. Pang, Y. L. Ling et al., "Research on network review mining based on improved feature extraction and clustering," Journal of Modern Information, vol. 2, pp. 68-74, 2018.

[34] W. Wang and H. W. Wang, "Feature comparison network for competitiveness: emotional analysis method," Journal of Management Science in China, vol. 9, pp. 109-126, 2016. 


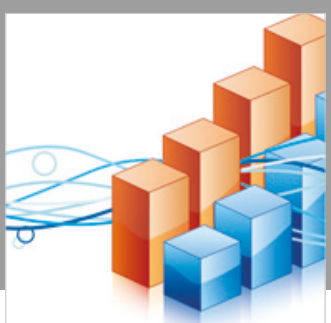

Advances in

Operations Research

\section{-n-m}
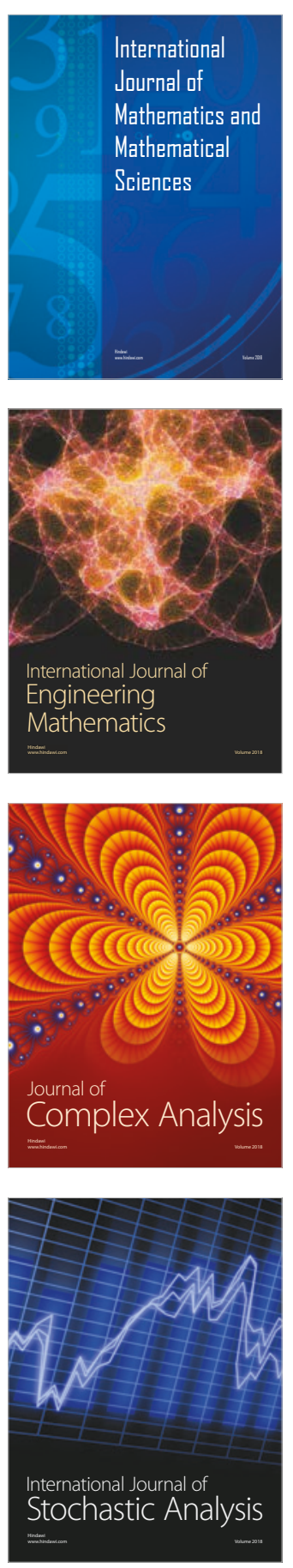
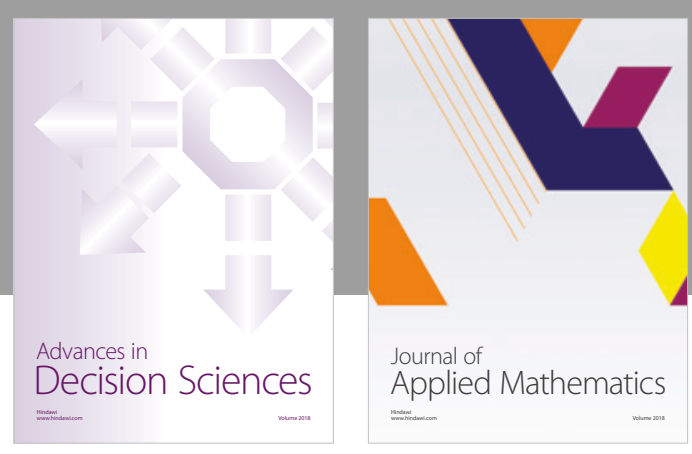

Journal of

Applied Mathematics
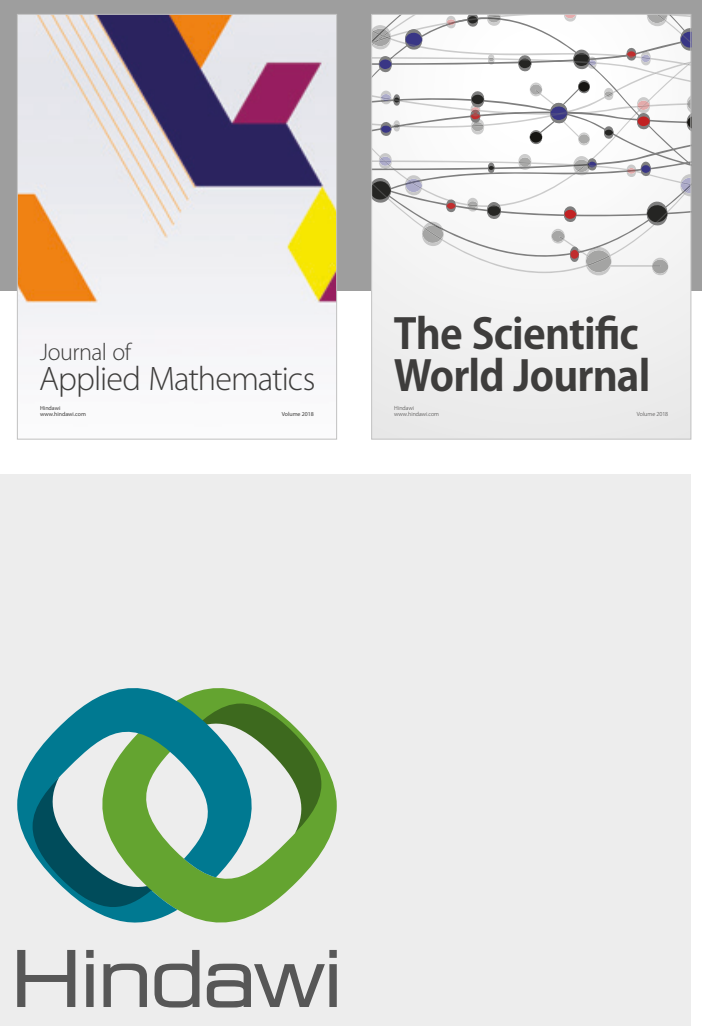

Submit your manuscripts at

www.hindawi.com

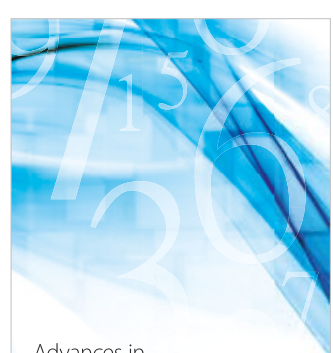

Advances in
Numerical Analysis
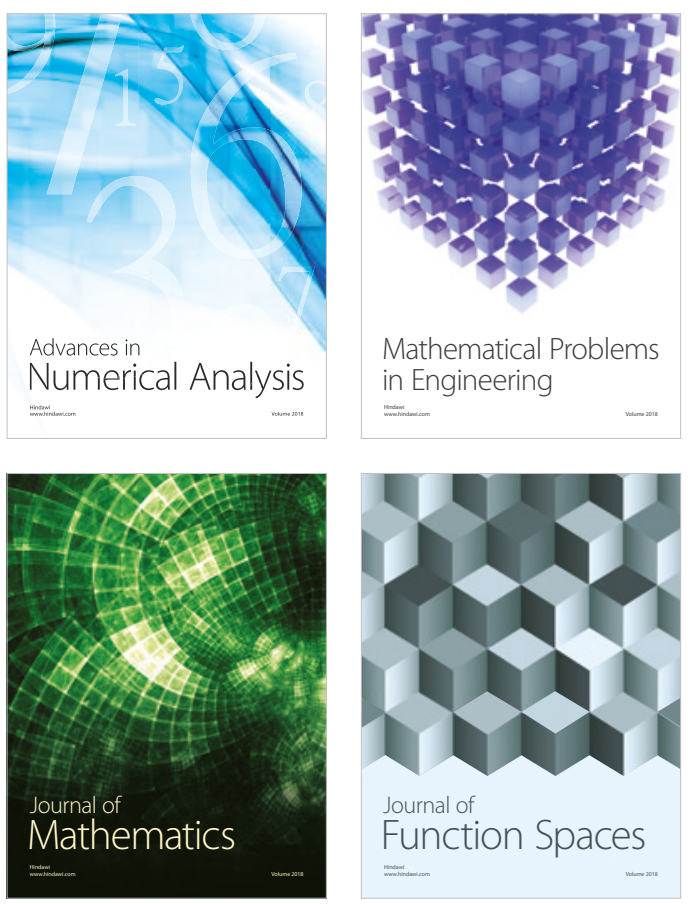

Mathematical Problems in Engineering

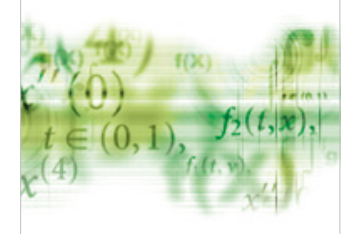

International Journal of

Differential Equations

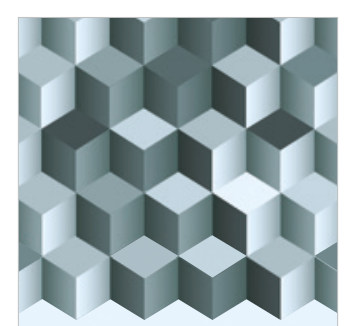

Journal of

Function Spaces
The Scientific

World Journal

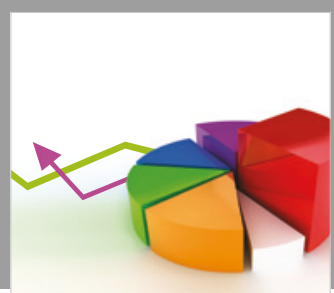

Journal of

Probability and Statistics
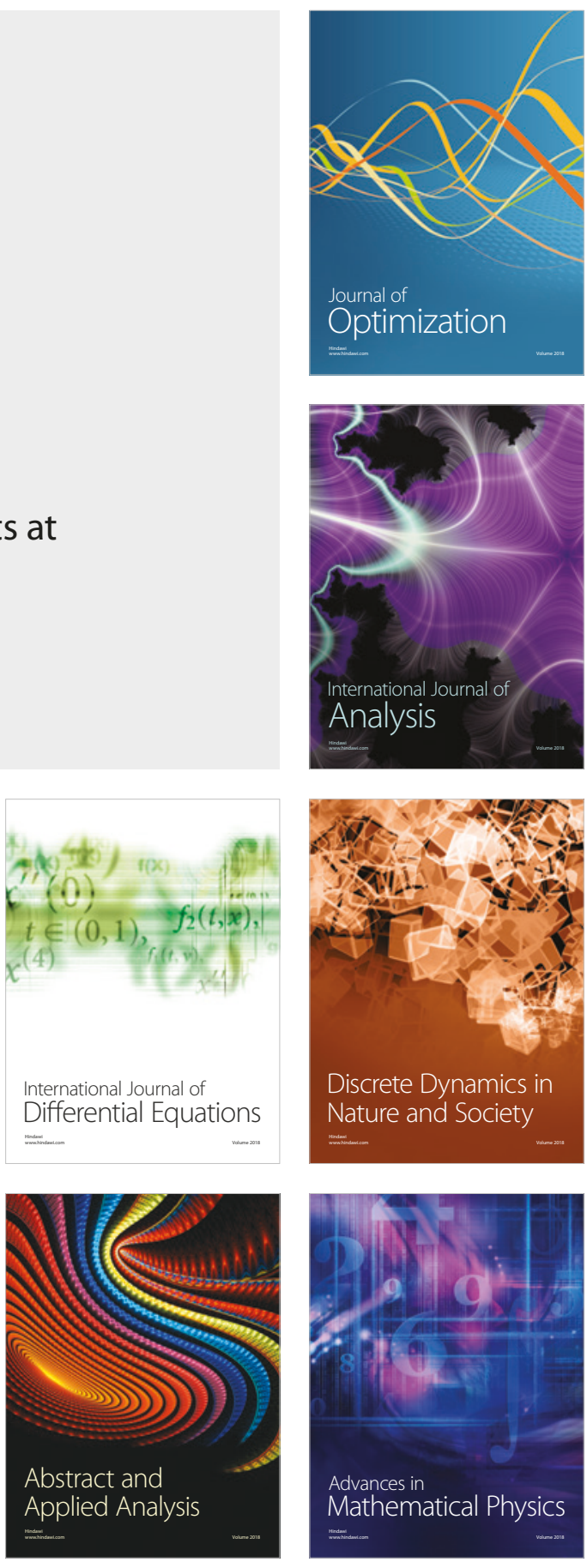